\title{
LINKS AND HYPERLINKS: \\ AN EMPIRICAL ANALYSIS OF INTERNET PORTAL ALLIANCES, 1995-1999
}

\author{
Dan Elfenbein \\ Josh Lerner \\ Working Paper 8251 \\ http://www.nber.org/papers/w8251 \\ NATIONAL BUREAU OF ECONOMIC RESEARCH \\ 1050 Massachusetts Avenue \\ Cambridge, MA 02138 \\ April 2001
}

We thank Mark Edwards of Recombinant Capital and Seth Segel of Media Metrix for access to their organizations' data. Drew Fudenberg, Rich Gilbert, Ariel Pakes, and Jean Tirole, and seminar participants at Berkeley, Harvard, and the IDEI conference on the Economics of Software and the Internet provided helpful comments. Harvard Business School's Division of Research provided financial support. The views expressed herein are those of the authors and not necessarily those of the National Bureau of Economic Research.

(C) 2001 by Dan Elfenbein and Josh Lerner. All rights reserved. Short sections of text, not to exceed two paragraphs, may be quoted without explicit permission provided that full credit, including $\odot$ notice, is given to the source. 
Links and Hyperlinks: An Empirical Analysis of Internet Portal Alliances, 1995-1999

Dan Elfenbein and Josh Lerner

NBER Working Paper No. 8251

April 2001

JEL No. L14

\begin{abstract}
$\underline{\text { ABSTRACT }}$
This paper examines the structure of over 100 alliances by Internet portals from 1995 to 1999. These alliances were an attractive empirical testing ground because of the large number and heterogeneous nature of the contracts, the high standards for disclosure in the industry, and the careful delineation of ownership, control, exclusivity, and other provisions in the contracts. The division of ownership and allocation of control rights displayed patterns consistent with the predictions in the incomplete contracting literature. Similarly, the exclusivity of the agreements appeared to vary, at least weakly, with the value of the product or service being made available to the portal, consistent with the licensing literature. In other cases, particularly in regard to the differing allocation of ownership and control and the varying completeness of the contracts, the empirical patterns indicated a more complex world than the one that theory led us to anticipate.
\end{abstract}

Dan Elfenbein

Harvard Business School

Sherman Hall, Room 205-3

Boston, MA 02163
Josh Lerner

Harvard Business School

Morgan Hall, Room 395

Boston, MA 02163

and NBER 


\section{Introduction}

The transfer of technology between firms has attracted extensive theoretical attention. The depictions of these transactions rely on a diverse set of assumptions about the essential problems that the contracting firms face, and often reach diametrically opposed conclusions. Despite the evident conflict between the various theoretical depictions and the important role that alliances and licensing play in many hightechnology industries, the structure of these agreements has attracted surprisingly little empirical attention.

This analysis took a comprehensive view of the development of alliances by Internet portals from 1995 to 1999 . Using a sample of over 100 contracts, we examined the determinants of contract structure. We studied how the division of ownership, allocation of control rights, contractual completeness, extent of exclusivity provisions, structure of payments, and alliance length varied with the circumstances of the contracting parties.

Portal contracts provided an attractive empirical testing ground for three reasons. The first was the large number and heterogeneous nature of the contracts. Hundreds of consumer-oriented Internet companies went public during the second half of the 1990s. Many of these completed IPOs while still in their formative stages. Many incumbent companies also launched Internet initiatives. As a result, the contracting parties ranged from well-established corporations to very young entities. 
Second, the standards for disclosure in this industry have been high. Publicly traded entities are required to file all "material" contracts. Due to the relatively limited revenues of many portals and other Internet concerns and the significant impact that announcements concerning alliances have had on these firms' share prices, the disclosure of agreements during this period was extensive. While firms could request confidential treatment for portions of the alliance agreements, their failure to disclose might become an issue if the firm was subsequently subject to shareholder litigation.

The final attractive aspect was the nature of the contracts themselves. As will be discussed in detail below, these agreements carefully delineated ownership, control, exclusivity, and other provisions. The close mapping between the topics considered in these agreements and in the theoretical depictions of contracting made this a natural empirical testing ground.

In order to examine theoretical suggestions, we studied how various contractual terms varied with firm characteristics. In univariate and regression analyses, five conclusions emerged:

- The division of ownership displayed a pattern consistent with the predictions in incomplete contracting literature, such as Grossman and Hart [1986]. The ownership of critical elements such as the web site address and the customer data was typically assigned to the party whose effort was most critical to the success of the agreement.

- The allocation of control rights appeared most sensitive to the bargaining power of the two contracting parties. The theoretical literature often does not make a clear 
distinction between the division of ownership and control. In the portal agreements, however, control was assigned in a somewhat different manner than ownership: most critical appears to be the relative financial and product market strength of the two parties. This division of control was consistent with Aghion and Tirole [1994] (though this model is framed in terms of ownership rather than control).

- The degree of contractual incompleteness varied considerably across the agreements. Models of contracting between a principal and agent often assume that the output or performance cannot be stipulated in an enforceable contract, but some assume that project output can indeed be contracted upon. In this industry, there appeared to be many observable measures of performance and effort. The agreements included on average one provision each relating to the product market and technical performance of the alliances. Why the contracting parties would fail to include all such provisions in agreements, if indeed they were enforceable, was not obvious.

- The exclusivity of the agreements appeared to vary weakly with the value of product or service being made available to the portal. In the spirit of predictions by Kamien and Tauman [1986] and Gallini and Wright [1990], cases where the partners' web site was in greater demand were associated with more restrictions that made the agreement an exclusive one. In addition, when the portal had relatively greater product market strength, more restrictions were placed on the partner. In this sense, exclusivity behaved much like the control provisions mentioned above.

- The final dimensions examined, compensation structure and contract length, displayed relatively little consistency. It was unclear whether the poor results 
stemmed from a failure of the contracts to correspond to theoretical descriptions or the poor nature of our measures.

The plan of this paper is as follows. In Section 2, we provide a brief overview of Internet portals and the alliances into which they enter. In Section 3, we review the relevant theoretical economics research, which frames the empirical analyses. We describe the creation of the data set in Section 4. Section 5 presents the analyses, and the final section concludes the paper.

\section{Portals and Portal Alliances}

Portals - which can be defined as Internet sites that provide (directly or indirectly) a broad array of services and linkages to users - are a relatively new organizational form and, like the Internet, have grown rapidly. The first portals began operations in 1994, shortly after the introduction of the World Wide Web and the widespread diffusion of the Internet browser. In May 2000, twenty publicly-traded portals reached a combined market capitalization of over $\$ 250$ billion. At that time, portals represented 13 of the top 15 U.S. web sites, with the leading U.S. portal receiving visits from 50 million unique users per month.

Many of these sites, such as Yahoo!, originated as classified collections of links to other web sites. Others, such as Lycos, began as search engines, enabling users to locate web sites on certain topics or featuring specific phrases. While many portals were new entrants, others had previously operated proprietary on-line services (for instance, 
America Online). Although subscribers to these proprietary services initially had access only to the features developed for the service itself, these firms increasingly began providing Internet access and created portals of their own. Finally, producers of browser software developed portals to take advantage of their products' placement on the desktop.

Beginning in 1997, portals began adding a broad array of materials to their sites. These included content, such as stock prices and news headlines, as well as services, such as on-line auctions and personal e-mail. The evolution of the services offered by portals is illustrated by Figure 1, which displays the evolution of Yahoo!'s homepage between 1994 and 1999. The basic services were typically available for free. Portals generated revenues principally through the sale of banner and sponsorship advertisements. Many portals also sought to diversify their revenue bases with transaction fees from merchandise sold on their sites by strategic partners and through other means. ${ }^{1}$

Alliances, therefore, benefited a portal in two ways. First, in exchange for advertisements, promotions, and other services, the portal received direct compensation. Second, the agreements may have increased the appeal of the portal's site by deepening its content and extending its features. These new features, which the portal had neither the time nor skills to develop itself, could attract new users and could also encourage more frequent or longer visits by existing users, thereby providing more opportunities to display ads. In addition, during the years under study, analysts often considered

\footnotetext{
${ }^{1}$ Gandal [2001] examines competition within the search engine segment of the portal industry and finds that while first mover advantages were important in attracting unique visitors, search engines competed on the quality of search services, which became an increasingly important determinant of traffic over time.
} 
measures of web site traffic such as the number of unique visitors per month and the average number of minutes per user per month in establishing recommended valuations for portals.

Alliances were also useful for the partner firms, be they content, service, or technology providers. Many Internet sites struggled during this period to acquire a sufficient user base. In many segments of the Internet industry, analysts predicted that there would be a substantial shake-out, in which only one or two leading firms would survive and emerge as profitable. Portal alliances were one method of attracting users. Alliances also often permitted partners to rapidly test their business models and to acquire customer data. Even if they were executed on relatively unattractive terms, alliances could thus be beneficial for the partners as well.

The alliance agreements themselves were, in general, complex. For example in December 1998, Autoweb.com, which operates a site that allows users to research new automobiles and purchase them online, entered into a 13-month advertising and promotion agreement with Yahoo!. The agreement specified the types and placements of Autoweb.com links on the Yahoo! site, including banner and button placement, a link allowing users to search Autoweb's site, and links within Yahoo!'s auto classifieds service. Yahoo!, for its part, would be solely responsible for the user interface and graphic display of Autoweb links. Limited exclusivity provisions were built into the agreement. The contract prohibited Autoweb from displaying any links to Yahoo!'s 
competitors on its front page. ${ }^{2}$ Yahoo!, in turn, was prohibited from including graphic links to more than three other auto merchants, and was prohibited from displaying banner advertisements from any competitor on specified pages. Payment and performance provisions were also specified. The contract detailed the number of impressions ${ }^{3}$ that Yahoo was to deliver (by type of advertisement); it granted Autoweb access to a database where these impressions would be calculated; and it described the contingencies that would result should Yahoo fail to deliver the required number of impressions during the term of the agreement. As compensation, Yahoo received a fixed slotting fee and a referral fee for each click-through ${ }^{4}$ under the agreement. This agreement did not involve the creation of a new site but rather focused on the links between two existing sites. Thus, the discussion of ownership was naturally limited; each party merely affirmed its ownership rights over the user data that it collected in the course of operations.

By contrast, an agreement signed between Lycos and Autobytel.com, an Autoweb rival, in February 1999 had a completely different structure. This agreement created a co-branded version of the Autobytel site for Lycos users. The co-branded site would have "the [A]utobytel 'look and feel' but with Lycos' logo displayed on the home page and each page related to new car buying." The creation of this new site required provisions about who would design, operate, serve, and pay for the site (Autobytel in all

\footnotetext{
${ }^{2}$ The competitors Yahoo specified were Amazon, eBay, Excite, Lycos, Microsoft, America Online, Netscape, CNET, and Infoseek.

${ }^{3}$ An impression is recorded each time each time an advertisement appears in a page viewed by a user.

${ }^{4}$ A click-through occurs when a user follows a displayed link to another site.
} 
cases). The contract guaranteed Autobytel a minimum number of impressions, but also granted an unlimited number of links resulting from over 100 search terms, for which Lycos would provide exclusivity. (These search terms included misspellings such as "Alfa Romero" and colloquialisms such as "beemer.") In return for these links, Autobytel paid a fixed fee and would pay an additional transaction-based royalty for each purchase request over a specified number submitted by Lycos' customers on the Autobytel site. ${ }^{5}$ To ensure compliance, each firm was given audit rights to examine the others' records. Autobytel retained rights to all customer data, but agreed to provide aggregated customer profile data for Lycos.

As the examples above suggest, there was a great deal of heterogeneity in the alliances that portals entered into. In some cases (e.g., promotion agreements), the portal undertook most of the effort after the alliance signing. In others, such as agreements in which the partner made a technology or service available to the portal's users, the bulk of the responsibility fell on the partners' shoulders. Furthermore, as these two alliances illustrate, issues of ownership, control, exclusivity, term length, performance guarantees, and compensation are important features of nearly every contract and vary substantially by portal, partner, and contract type. We examine these differences systematically below.

\section{Theoretical Predictions}

A substantial body of work examines the licensing of intellectual property and research joint ventures. This literature relies on a diverse array of assumptions and

\footnotetext{
${ }^{5}$ The number of impressions and the magnitude of the fees were redacted from the publicly filed versions of both contracts.
} 
suggests a variety of empirical implications. Many of the works on technology licensing have focused on the question of how the option to license discoveries (as well as to engage in joint ventures before R\&D has been undertaken) affects firms' decisions to pursue innovations. While this question is an interesting one, it is less relevant to our analysis. ${ }^{6}$ Rather, we will discuss works that examine licensors' attempts to maximize the value of their licenses by varying the terms of the agreements, such as exclusivity, control rights, and payment structure.

Kamien and Tauman [1986] consider a setting where an inventor is licensing a discovery to a number of potential users under full information. In a setting where firms have some market power (i.e., under Cournot competition), the inventor should only license the most drastic innovations on an exclusive basis. In these cases, the author suggests, the inventor should sell the invention for a flat fee.

Gallini and Wright [1990] relax the assumption of full information, and reach a diametrically opposite conclusion: when the inventor has private information about the value of the invention, he will always ask for an output-based reward. In a case of an innovation that can be readily imitated, they suggest that the inventor will license the invention on either an exclusive or non-exclusive basis and receive a linear share of the revenues from the discovery. A major innovation that is difficult to imitate, they predict, will be licensed exclusively with an increasing royalty rate as sales rise.

\footnotetext{
${ }^{6}$ Indeed, in order to explore these issues, many papers examine only particular types of licenses: e.g., Katz and Shapiro [1985] focus on a case where licensors are compensated by a fixed fee and agreements are non-exclusive.
} 
Hall [1991] considers the impact of moral hazard problems: in particular, the possibility that the licensor will undertake a subsequent license of a close substitute to another licensee. In the absence of moral hazard, he suggests, a result similar to that discussed by Kamien and Tauman will hold. Once moral hazard is introduced, however, the result changes. When royalties are employed, the temptation for the licensor to license a similar technology to another party is greatly reduced. Hall predicts that royalties should be used in some-though not in all-exclusive and non-exclusive licensing agreements.

With the exception of Hall [1991], the above papers assume the actions of the licensor can be observed and the licensing agreements enforced. Numerous more general contracting models, beginning with Grossman and Hart [1986] and Hart and Moore [1988], consider a setting in which the inability to observe effort and enforce agreements creates severe problems. ${ }^{7}$ A typical assumption is that it is impossible for the two parties to write a verifiable contract which could be enforced in a court of law and which specifies the effort and final output of the two parties. This is because there are many possible contingencies, all of which cannot be anticipated at the time the contract is drafted. Due to this contracting problem, these models argue that it is optimal for ownership of the project to be assigned to the party whose effort has the greatest marginal impact on the outcome. This owner, who retains the right to make the decisions that

\footnotetext{
${ }^{7}$ Holmström and Roberts [1998] argue that a variety of factors other than an inability to specify a complete contract may affect the formation and structure of alliances. These include the need for information transfers and the extent of agency problems. As the authors note, however, the impact of these factors needs further theoretical attention.
} 
cannot be specified in the contract, gains bargaining power from asset ownership that enables him to appropriate a majority of the surplus that results from the project. Because of this incentive, the party will make the decisions that maximize-or come close to maximizing - the returns from the project. This conclusion is quite different from that of traditional studies of interactions between principals and agents (e.g., Holmström [1979]), who generally conclude that the incentives offered the contracting parties (cash flow rights) are critical, but not the allocation of control rights.

Aghion and Tirole [1994] adapt this general model to an R\&D alliance between two firms. In their basic model, the authors assume that the research unit is without financial resources of its own, cannot borrow any funds, and has no ability to commercialize the innovation itself. As a result, it turns for financing to a customer, a firm that may intend to use the product itself or to resell it to others but cannot make the discovery independently. The success of the research project is an increasing function, though at a decelerating rate, of both the effort provided by the research unit and the resources provided by the customer. Developing a contract between the two parties is challenging. While the ownership of the product can be specified in an enforceable contract, and the resources provided by the customer may also be so specified, uncertainty precludes writing a contract for the delivery of a specific innovation. Similarly, an enforceable contract cannot be written that specifies the level of effort that the research unit will provide. 
Aghion and Tirole consider two polar cases: when the research unit has the $e x$ ante bargaining power, and when the customer does. When the research unit has the bargaining power, the ownership of the research output will be efficiently allocated. If the marginal impact of the research unit's effort on the innovative output is greater than the marginal impact of the customer's investment, then the research unit will receive the property rights. If not, the research unit will transfer ownership to the customer in exchange for a cash payment. This result is similar to that of Grossman and Hart [1986].

When the customer has the bargaining power, however, a different pattern emerges. If it is optimal for the customer to own the project, it will retain the project. If, however, it would maximize innovation for the property rights to be transferred to the research unit, the ideal outcome will not be achieved. In particular, the customer will be willing to transfer ownership, but the cash-constrained research unit will not have enough resources to compensate the customer. As a result, an inefficient allocation of the property rights occurs, with the customer retaining the rights to the invention. ${ }^{8}$

Although the model presented by Aghion and Tirole deals formally with two parties, its results generalize to the case in which the upstream (or the downstream) party

\footnotetext{
${ }^{8}$ Baker, Gibbons, and Murphy [2000] make a related set of predictions, which will not be tested in this paper. Rather than focusing on liquidity constraints, they allow the licensor to undertake multiple actions. Simply put, the firm may focus its effort on increasing the value of its innovation for the licensee, increasing the value of its innovation in an alternative use not covered by the license, or some combination of both actions. As in other models that allow for multi-tasking, when the marginal impact of the licensor's effort on the value of the asset in its alternative use is high, vertical integration is most efficient. When non-integration is called for, the nature of the optimal relationship will depend primarily on the two firms" "patience."
} 
has multiple potential trading partners. The number and quality of these partners, on both sides of the market, determine the relative bargaining power of the firms, which is incorporated into the model in reduced form. This is an important consideration given that both portals and partners almost surely have multiple potential partners.

\section{The Data Set}

To undertake the analysis, we identified a set of 106 contracts between portals and other firms entered into between 1995 and 1999. These contracts were identified primarily from Recap/IT, a consulting firm that maintains a database of contracts involving Internet, technology, and telecommunications firms. Publicly traded Internet firms, like other concerns, are required by the U.S. Securities and Exchange Commission (SEC) to file material documents. Internet companies tend to interpret this requirement conservatively, and often file alliance contracts. Recap/IT identifies alliances from press releases, analyst reports, and reviews of SEC filings. Their database includes links to the filings of these firms detailing each agreement.

Because all contracts in the database (and the analysis) had been deemed "material" and filed with the SEC, a natural question is what type of selection biases are at work. Typically, alliances are considered "material" for firms with limited revenues or assets: a definition of materiality is that "there is a substantial likelihood that a reasonable shareholder would consider it important in making an investment decision." Since we can observe agreements filed by either party, the only subset of agreements that we cannot observe are those between two established firms. For example, analyst reports 
suggest that America Online and Yahoo! signed alliances with several large retail banks in 1998 and 1999. These agreements were not filed with the SEC by either party, and are thus not included in our sample. It is not clear ex ante what bias will be introduced by our sampling technique.

For our analysis, we selected a random sample of 106 alliances from this database. We sought to create a population that avoided undesirable heterogeneity. In particular, we eliminated alliances where:

- One of the parties was non-profit organization.

- One of the parties had a controlling interest in the other, either through a majority equity stake or through a purchase option.

- The two parties had a previous alliance covering the same set of technologies, and consequently were renegotiating the terms of an earlier alliance.

We reviewed these documents carefully to identify the key features of these agreements. After considerable experimentation, we developed a coding form that captured the key features of these alliances. In many cases, firms filed multiple copies of the same documents with the SEC. In these cases, different versions of the documents were reviewed to insure that information that was redacted in one version was not included in another.

We also gathered two types of supplemental information. First, to assess the financial health of the contracting parties, we examined the Compustat and Worldscope 
databases for the end of the fiscal quarter immediately prior to the alliance. For firms where this information was not available from Compustat or Worldscope, we gathered the information from 10-K filings, IPO prospectuses, and other securities filings.

Second, we employed information from an Internet and on-line usage tracking service, Media Metrix (formerly known as PC Meter), which has compiled information from the earliest days of the industry. ${ }^{9}$ For each of the two contracting parties, we assessed their Internet properties" "reach"- the percentage of all U.S. users who accessed the site at least once in a given month — and the total number of days and minutes that the average accessing user viewed the site in that month. In making these calculations, we compiled all properties owned by the contracting firm: for instance, the usage data for an alliance signed by Disney in 1999 would include information about visits to ABC.com.

Table 1 summarizes the sample of agreements used in this analysis. In Panel A, the date of the agreements is tabulated. The agreements were concentrated in the second half of the period under study. This reflected the acceleration in the level of Internet activity over the course of the 1990s.

Panel B summarizes the relative effort required in the alliance. We examined five activities that frequently were required after the agreement was signed: the development

\footnotetext{
${ }^{9}$ Media Metrix determined usage by examining the activity of a representative panel of Internet users. The size of the panel and accuracy of the measures has increased over time. We used data on U.S. users only: while in recent years, Media Metrix has introduced statistics on non-U.S. Internet usage, these were not available for the entire period. During the period under study, U.S. users had a dominant presence at most commercial Internet sites.
} 
of material for the site (whether content, services, or technology), the maintenance and hosting of the site, the provision of customer service, order fulfillment, and billing. We coded these as +1 if the portal was required to make the greater effort on this dimension, -1 if the partner was required to do so, and 0 if the effort was jointly shared or not required by the agreement. While the sum of these five effort measures ranged from +5 to -5 , in most cases, the bulk of the post-agreement effort was required of the partner.

Panel $\mathrm{C}$ presents the traffic on Internet sites of the two parties in the month before the signing of the agreement. Not surprisingly, portals' sites were visited by more users, more frequently, and for longer than partners' sites.

Panel D considers the relative financial health of the two parties. There was a great deal of variation, which reflected the fact that we examined the financial health of the entire corporate entity if it had $100 \%$ ownership of the contracting firm. For instance, in a transaction involving Snap.com, the financial information of its parent, General Electric, was recorded.

The relationship between selected contract provisions is presented in Appendix Table A1. Each provision was coded as +1 if present in the contract and as 0 otherwise.

\section{The Analysis}

In the analyses, we examined the alliances along six dimensions. We also studied how the features of the alliances varied with the circumstances of the contracting parties. 
In each table, we divided the observations by four measures: the date of the agreement, the relative effort required of the two parties, the relative traffic on the two parties' Internet sites (as measured through the sites' reach), and the relative financial strength of the contracting parties (as measured through revenues in the previous four quarters). ${ }^{10}$

The first two measures were divided roughly into thirds: we placed approximately the same number of observations in each of the three time and effort categories. It did not, however, make as much sense to divide the traffic and financial measures in this way. For instance, it was unclear whether a distinction between a portal that was visited five times more often than the partner and one that was visited ten times more often was very meaningful. Thus, we divided the observations into those where the portal was visited at least three times more often or had three times greater revenues than the partner, those where this held for the partner, and intermediate cases. As a result, the number of observations in these cells was not even. In particular, there were relatively few cases where the partner had significantly greater reach than the portal. ${ }^{11}$

One potential problem that the analysis faced was non-independence of the observations. In particular, a number of portals appeared frequently in the sample. While the alliance agreements of the portals were certainly not identical, we suspected

\footnotetext{
${ }^{10}$ In choosing the measures for the cross-tabulations, we opted for the most readily available measures. In the regression analyses, we examined the robustness of the results to the use of alternative measures.

${ }^{11}$ In the cases where site visitation (or revenue) data were missing, we assumed that the other party had greater reach (or revenues). We corroborated this assumption by examining the reported site visits (or revenues) once the partner began to be reported by Media Metrix (or revealed its financial position in later SEC filings).
} 
that there might have been common elements across the agreements of each portal. In the regression analyses, we addressed this concern by calculating heteroskedastic-corrected standard errors (grouped by each major portal). We also included dummy variables in many regressions for each of the seven portals most frequently represented in the sample (America Online, Excite, iVillage, Lycos, Microsoft Network, Netscape, and Yahoo!) to control for the presence of portal-specific effects.

\section{A. Ownership}

We began by considering the ownership of the agreement. Ownership, a critical concept in the theoretical depictions of incomplete contracting discussed above, was manifested in three ways in these alliances. First, and perhaps most directly, the URL (the Uniform Resource Locator, or the Internet address) may have been assigned to one or the other parties. Second, the servers may have been designated as the property of one or the other parties. Third, the customer data (if any) may have been assigned to one or the other parties. In each case, we coded the variable as +1 if ownership was assigned to the portal, -1 if assigned to the partner, and 0 if there was joint ownership or the ownership provision was not applicable. ${ }^{12}$

\footnotetext{
${ }^{12}$ One question about the multiple measures of ownership in this analysis (and the other measures used below) is the extent to which they are correlated. If they were closely correlated, the independence of the individual tests would be suspect. The measures were positively correlated, but certainly not perfectly: the mean correlation coefficient of the ownership measures was 0.30 . This correlation was considerably less in the analyses below: for instance, the average correlation coefficient of the twelve control measures was 0.07 .
} 
Table 2 summarizes the allocation of ownership. Ownership did not display a significant pattern across time, or with relative traffic or revenues of the two parties. But there was a sharp difference with who provides the greatest effort in the alliance. Panel D reports that among the alliances where the partner made the greatest effort after the agreement was signed, 1.6 more ownership rights (out of the possible three) were assigned to the partner. Among those where the portal made the greatest effort, 1.0 more ownership rights were assigned to the portal. For each of the ownership provisions analyzed, the effects were significant at the one-percent confidence level. The division of ownership was quite consistent with the predictions in incomplete contracting literature, such as Grossman and Hart [1986].

These patterns were corroborated in regression analyses, which analyzed the sum of the three ownership rights. We employed an ordered logit specification. This specification avoided some of the problems posed by the differing importance of the various control rights. Such a regression methodology treated an alliance assigning two ownership rights to the portal as more favorable to the portal than one with one such rights, but not necessary twice as favorable.

In each of the regressions reported in Table 3, the relative effort was positive and statistically significant. The effects were large as well: at the mean of the independent variables, a one standard deviation increase in the effort variable shifted the predicted allocation of ownership from an even division to +1 (one additional ownership right assigned to the portal). Similarly, a one standard deviation reduction in effort led to a 
predicted ownership of -1 . The results were robust to the use of alternative measures for the relative popularity of the two parties' sites and their relative financial condition, ${ }^{13}$ as well as to the addition of controls for the type of transaction and the portal. In unreported regressions, we employed an ordinary least squares specification rather than an ordered logit one, and added controls for the age of the portal and partner. The results continued to be robust to these changes. In further regressions, we analyzed several sub-samples of alliances and found ownership to be highly sensitive to allocation of effort in each case. ${ }^{14}$

\section{B. Control}

We then identified twelve major aspects of the governance of the agreements. The first set were control rights that could be assigned to either party (at least in theory).

\footnotetext{
${ }^{13}$ The sample size shrank when we used the difference between the financial measures or especially the site popularity measures. This is because we did not include observations in these regressions where one of the parties was missing data, which frequently was the case for newly established partners.

${ }^{14}$ The individual provisions that were used to form the relative effort metric varied somewhat in their applicability across the sample. In many alliances, each of the five effort provisions was relevant. In others-for example an agreement between Reuters and Infoseek to provide news content-effort provisions such as order fulfillment, billing, and customer service were not relevant. The relevance of the effort provisions might depend on two factors. First, if the alliance created a new, co-branded space, it was more likely that all five effort provisions would be relevant to the agreement. In agreements where no new co-branded space was created, it was less likely that all would apply. Second, if the alliance focused on product sales, it was most likely that all five effort provisions would apply. If the alliance focused on a service, at least three of the effort provisions were likely to apply, and for alliances focused on content, two were likely to apply. To ensure that a single subset of these contracts was not driving the empirical results described above, ordered logit regressions were performed on each of the five separate sub-samples. Table A2 in the Appendix reports the coefficients and robust standard errors on the relative effort variable for each of these sub-sample regressions. In the basic specification, relative effort was both economically and statistically significant in each of the sub-samples, and with the exception of service agreements, relative effort remained significant when relevant controls for deal type and portals could be added.
} 
First, the lines-of-business that one of the parties could engage in were sometimes restricted. One of the parties may have reserved the right to approve all content that the other prepared as part of the agreement, to post a set of standards to which the other party had to conform, or to determine the "look and feel" of the site. One of the parties may have been required to mention the other (or the co-branded pages) in any advertising of its own web site or to submit all advertising to the other party for approval. These provisions were coded as +1 if this provision favored the portal, -1 if it favored the partner, and 0 if neutral.

The second set of control rights specifically limited the activities of the partner. Several of these sought to insure that portal's users would have minimal disruption when visiting the site: the partner may have been required to optimize the site for viewing by a certain browser, to use a certain software package in the construction of the site, to employ certain navigation devices (e.g., frames), and to make a "good faith" effort to return visitors back to the portal. Finally, in some cases, the portal either made an equity investment in the partner or reserved the right to attend its board meetings. These rights were coded as +1 if present and 0 if absent.

Table 4 analyzes the distribution of control rights. Unlike the depiction in the theoretical literature - which often does not make a clear distinction between the division of ownership and control- here a distinct pattern appeared. The effort required of the portal did not appear to have a linear effect on the allocation of control. As Panel M 
reports, it was those agreements near the median in the division of effort where the most control rights were granted the portal.

Rather, the bargaining power of the two contracting parties appeared to have the most dramatic impact on the allocation of control rights. For six out of twelve control rights, when the portal had much greater revenues than the partner, significantly more rights were assigned to the portal. These results continued to hold when we examined the aggregate number of control rights granted in Panel M. In a similar vein, when portals had significantly more reach, they obtained more control rights. As discussed above, Aghion and Tirole [1994] suggest that, among other considerations, the relative bargaining power of the two parties will impact the allocation of ownership (and hence control) over an alliance. The pattern of control right allocation was consistent with their suggestion, though the differing patterns of ownership and control seen here was not discussed in their work. The pattern was also consistent with the biotechnology alliances analyzed by Lerner and Merges [1998].

These results continued to hold when we examined the patterns in a regression analysis. Once again, we employed the sum of control rights as the dependent variable in an ordered logit regression. The measure of the relative visitations to the two parties' sites remained significant, whether we used the composite measure discussed in the introduction to this section or the difference between the two parties on several dimensions. Again, the results were significant economically. In the leftmost regression, at the mean of the other independent variables, a shift from the partner having a greater 
reach than the portal to an even division changed the predicted division of control rights from being on a borderline between an even division and +1 to having one control right assigned to the portal. When the portal had the greater reach, the predicted allocation of control rights was +2 . The results were robust to the various changes to the specification described in Section A.

Bargaining power is not the only explanation for the division of control rights that is observed in the sample. One alternative explanation is that control rights are introduced into a contract to mitigate franchise risk. Many alliances may entail significant franchise risk: poor performance or even non-performance by one party may reduce the value of the other's brand. In this way, franchise risk would enter into the firm's profit function and would be addressed explicitly in the bargaining process. If reach is good proxy for brand strength, then it might be efficient for more control rights to be allocated to the party with more at stake.

Because some of the control provisions are more likely to mitigate franchise risk than others, the data set does give us some ability to distinguish between the two theories. ${ }^{15}$ Toward this end, we generated two alternative composite control measures. First, we excluded provisions related to content restrictions from the composite control measure; in the resulting regressions, relative reach remains significant in the basic specification and after the addition of deal type and portal controls as well as in

${ }^{15}$ For example, some control provisions, such as approving all of the partner's content, seemed designed to mitigate franchise risk, while others, such as allowing for frames to be used did not. 
regressions using alternative measures of relative reach. Table $\mathrm{A} 3$ in the appendix reports these results. Second, we excluded provisions related to both content restrictions and provisions relating to control over "look and feel" from the composite control measure. After making this adjustment, relative reach is nearly significant at the $\mathrm{p}<0.1$ level in the basic specifications and is not significant when controls for deal type are added. When alternative measures of relative reach are used on the subset of alliances for which they are available, however, relative reach is highly significant. Table A4 in the appendix reports these results. Moreover, in these regressions, relative financial strength, another potential measure of bargaining power, is highly significant. Thus, stripping away the issue of franchise risk, relative bargaining power still seems to have an impact on the allocation of control rights, consistent with Aghion and Tirole [1994].

\section{Contractual Completeness}

Third, the completeness of the contract varied. While in some cases, the performance of each party in the agreement was left unspecified, in others, the performance was quite carefully delineated.

These contractual terms had two dimensions. The first related to the minimum level of commercial activity that the site, content, or service covered by the agreement needed to reach. Targets included a minimum number of user impressions that the site would garner (whether all impressions or those of some targeted subset of users), "clickthroughs" into another area, revenues, or new customers. The second set of terms related to the technological performance. These included the speed with which the pages loaded, 
the percentage of time the web-site was available, the level of customer service, and the competitive ranking by specified third parties (e.g., a trade magazine) of the site relative to its peers. In case these levels were not reached, the agreement was typically terminated or renegotiated. These variables were recorded as +1 if the provision was present and 0 otherwise.

Table 6 presents the patterns of contractual completeness. Most striking was the heterogeneity in the use of these provisions. While about one commercial and one technical performance provision were included in the average agreement, there was a great deal of variation. Few consistent patterns appeared: for instance, we did not see contracts becoming more complete over time as the sophistication of the contracting parties developed. This pattern was similar to the venture capital stock purchase agreements examined by Kaplan and Stromberg [2000], who find state-contingent terms in a significant minority of agreements. Models of contracting between a principal and agent can be divided between those that assume that the output cannot be stipulated in an enforceable contract (e.g., Grossman and Hart [1986], Hart and Moore [1988]) and those that assume that output can indeed be contracted upon (for instance, Aghion and Bolton [1992]). The presence of these terms within some but not all agreements was puzzling.

A suggestive - though hardly conclusive- pattern emerged from the regression analyses, which examined the sum of market completeness and technical completeness provisions. In particular, the measure of technical completeness appeared to a certain extent to behave like the control rights discussed in Section B. When the portal had the 
stronger bargaining position (again, as measured through a greater number of visits to its web site) more technical provisions were included in the agreement. Even though they were typically written as bilateral in nature (e.g., either party could cancel the agreement if the up-time target was not met), in actuality these state-contingent measures may have been particularly valuable to the portal. For instance, a partner who was encountering server problems would be unlikely to wish to cancel an important alliance, but a portal might indeed want to do so. These valuable provisions might be subject to same type of bargaining issues as the control rights discussed by Aghion and Tirole [1994]: in cases when the portal had the bulk of the bargaining power, the alliances may have included more "pro-portal" completeness provisions than they might have ideally. This pattern was seen in the basic specification and using alternative measures of relative reach, but did not remain when controls for deal type and portal were added. ${ }^{16}$

\section{Exclusivity}

A fourth area was the extent of exclusivity in the agreement. We first considered restrictions on the portal. We tabulated whether the portal was restricted from entering into any or more than a set number of agreements with competitors; from advertising competitors anywhere on the site, in specific areas of the site, or on a continuous basis; from establishing any links to competitors' sites; and from granting the use of certain keywords or search terms to other firms. We similarly analyzed whether the partner was restricted from entering into any agreement with a competitor or agreements with competitors involving specific content; from advertising competitors anywhere on its site,

\footnotetext{
${ }^{16}$ In an unreported regression including only deal-type controls, relative reach was significant at $\mathrm{p}<.1$.
} 
in specific areas, or on a continuous basis; from promoting competitors more prominently than the portal; or from establishing any links to competitors' sites. In all cases, +1 denoted a case where this exclusivity provision was present and 0 where it was absent.

Table 8 summarizes the exclusivity of the agreements. Few distinct patterns appeared in the restrictions on portals. There were significantly more restrictions on the partners, however, when there was an asymmetry in relative site popularity between the two parties. Partners faced very few restrictions when site popularity was relatively similar. This pattern was significant in both the composite measure presented in Panel P and in five out of the seven individual exclusivity provisions examined. In the literature review above, we noted predictions by Kamien and Tauman [1986] and Gallini and Wright [1990] that in cases when licensors had more important (or radical) technologies, they would be better off licensing them on an exclusive basis. Greater exclusivity when the partner's technology is more frequently accessed appeared broadly consistent with their prediction but could be sensitive to one or two observations in the cross-tabulations. On the other hand, relative bargaining power also seemed to have an impact on partner restrictions. Like the control provisions and technical completeness provisions discussed above, more restrictions were placed on the partner when the relative reach of the portal increased. This, too, suggests that in this sample bargaining power may overwhelm efficiency concerns in circumstances like those described by Aghion and Tirole [1994]. ${ }^{17}$

\footnotetext{
${ }^{17}$ It may be pointed that the reported analysis was of relative rather than absolute importance of the licensed item. The predictions of Kamien and Tauman [1986] and Gallini and Wright [1990] focus on absolute importance, whereas Aghion and Tirole [1994] focus on relative bargaining power. When the cross-tabulation analysis was repeated grouping alliances instead by the reach of the partner (rather than the relative reach), the differences in partner restrictions were no longer significant. One explanation
} 
In the regression analysis reported in Table 9, no patterns emerged from examining the sum of exclusivity provisions restricting the actions of the portal or the partner in the regression analysis when relative reach was included as a monotonic variable. When relative reach was allowed to vary non-monotonically in the analysis of partner restrictions, however, the results were consistent with the dual explanation offered above. Dummy variables indicating greater partner reach and greater portal reach were both statistically and economically significant. These results remained robust when controls for deal type and portal were added in unreported regressions.

A further observation from the regression analysis is that exclusivity-whether restrictions on the portal or on the partner-tends not to be associated with service agreements. Service agreements are also less likely to be associated with compensation via fixed fees alone (see Table 10). Thus, in this sub-set of agreements, the use of some form of variable compensation may reduce some of the hazards that exclusivity is intended to mitigate. This result is in the spirit of Hall [1991], where royalties serve as a bond to prevent the licensor from selling a direct imitation to someone else.

\section{E. Compensation}

Perhaps the least satisfactory measure was that of the compensation paid as part of the agreement. We observed in almost all cases the direction of payments, both of the primary payment and secondary payments (if any) associated with the agreement. (These

is that efficiency is more likely to be a prime consideration when the relative bargaining power is even or in favor of the partner. 
were classified based on the expectations expressed in the agreements). We also observed whether the payments were fixed in advance, or whether they included a variable element. Unfortunately, the actual dollar amounts of the payments were frequently redacted, so we were unable to analyze these in depth.

Table 10 reports on the payment structures in the alliances. No consistent pattern appeared in the overall use of fixed $v s$. variable compensation or in payments based on advertising revenue or gross margin. But contingent payments based on sales and new customers were significantly more common when the partner's effort was more important.

These results, however, did not appear to be robust, as the regression analyses reported in Table 11 reveal. We estimated logit regressions for a variety of payment features. No patterns appeared when we compared fixed vs. variable compensation. Contingent payments based on sales were more common when the effort of the partner was more critical, but the effect was not robust to the addition of control variables. Payments based on new customers did not display a statistically significant pattern.

Although these results are disappointing, they are not surprising. In the theoretical literature, optimal payment schedules may be highly sensitive to other features of relationships, such as exclusivity and ownership. For example, in the model developed by Gallini and Wright [1990], the mix of fixed fees and royalties depends on exclusivity arrangements; both fixed fees and royalties may be used in equilibrium. The 
simultaneous interactions between multiple other endogenous parameters of contract design with payment structure are not well understood.

\section{F. Duration}

Finally, we examined the length of the agreement. Incomplete contracting theory — as discussed, for instance, in Hart and Holmström [1987]— suggested that longterm contracts would be less frequent in settings where ex post opportunism by one of the parties was a greater problem. One challenge we faced was that opportunism problems were not as clearly identifiable here as in the energy industry investments considered by Joskow [1987] and Crocker and Masten [1988]. ${ }^{18}$

The agreements in the sample almost always stipulated a minimum length before they could be renegotiated. Many included a number of renewal periods, which were typically contingent on the approval of one or both parties. We treated these renewals in several ways. First, we simply calculated the length of the agreement, assuming all renewal options were exercised. In addition, we considered cases in which one of the parties had the unilateral right to renew the alliance. We calculated the period that the partner could unilaterally extend the agreement, and similarly for the portal.

Table 12 summarizes the patterns in the length of the alliances. Here, agreements in which the portal had greater reach tended to be associated with longer contract length. This pattern is also suggested by the regression analysis, reported in Table 13. While

\footnotetext{
${ }^{18}$ In follow-on work, we hope to identify better measures of opportunism problems in these contracts.
} 
longer agreements appeared to have been negotiated when the portal had relatively greater reach, this result was not robust to the use of alternative measures. Thus, we could not draw firm conclusions in this arena. It is difficult to see what relationship greater portal reach may have with ex post opportunism problems.

\section{Conclusions}

This paper examined the development of alliances by Internet portals from 1995 to 1999. Using a sample of over 100 contracts, we studied how the division of ownership, allocation of control rights, contractual completeness, exclusivity provisions, payments, and alliance length varied with the circumstances of the contracting parties. These alliances were an attractive empirical testing ground because of the large number and heterogeneous nature of the contracts, the high standards for disclosure in the industry, and the careful delineation of ownership, control, exclusivity, and other provisions in the contracts. Several suggestive findings emerged from the analysis:

- The division of ownership displayed a pattern consistent with the predictions in incomplete contracting literature.

- The allocation of control rights appeared most sensitive to the bargaining power of the two contracting parties, consistent with theoretical work on joint ventures.

- The degree of contractual incompleteness varied considerably across the agreements, with state-contingent provisions appearing in some but not all agreements.

- The exclusivity of the agreements appeared to vary, at least weakly, with the value of product or service being made available to the portal, consistent with the licensing 
literature. Restrictions on the partner were also sensitive to the relative bargaining power of the parties, displaying a pattern similar to that of control provisions.

- Few systematic patterns were seen in compensation and contract length.

Many of the results were consistent with theoretical suggestions. In other cases, particularly in regard to the differing allocation of ownership and control and the varying completeness of the contracts, the empirical patterns indicated a more complex world than the one that theory led us to anticipate.

In the discussion above, we suggested several areas for further research. First, it may be that in some cases, our independent variables were too blunt to pick up the effects that were actually present. In future work, we hope to refine some of the measures that we employed here.

Another substantial opportunity is in examining licensing arrangements across industries. As we noted above, there were a number of striking differences between these arrangements and the biotechnology licenses analyzed in Lerner and Merges [1998]. Substantial opportunities exist to examine the differences in the structure of alliances across industries, and how they vary with the extent of information problems and the nature of the intellectual property rights. While Anand and Khanna [2000] represents a first step in this direction, considerable opportunities remain for further exploration of these issues. 


\section{References}

Aghion, Philippe, and Patrick Bolton, 1992, “An Incomplete Contracts Approach to Financial Contracting," Journal of Finance. 77, 338-401.

Aghion, Philippe, and Jean Tirole, 1994, “On the Management of Innovation," Quarterly Journal of Economics. 109, 1185-1207.

Anand, Bharat, and Tarun Khanna, 2000, "The Structure of Licensing Contracts," Journal of Industrial Economics. 48, 103-135.

Baker, George P., Robert Gibbons, and Kevin J. Murphy, 2000, "Relational Contracts and the Theory of the Firm," Unpublished working paper, Harvard University, Massachusetts Institute of Technology, and University of Southern California.

Crocker, Keith J., and Scott E. Masten, 1988, "Mitigating Contractual Hazards: Unilateral Options and Contract Length," Rand Journal of Economics. 19, 327-343.

Gallini, Nancy, and Brian Wright, 1990, "Technology Transfer under Asymmetric Information," Rand Journal of Economics. 21, 237-52.

Gandal, Neil, 2001, "The Dynamics of Competition in the Internet Search Engine Market," forthcoming in International Journal of Industrial Organization.

Girotto, Jay, and Jan W. Rivkin, 1999, "Yahoo!: Business on Internet Time," Case No. 9700-013, Harvard Business School.

Grossman, Sanford J., and Oliver D. Hart, 1986, "The Costs and Benefits of Ownership: A Theory of Lateral and Vertical Integration," Journal of Political Economy. 94, 691719.

Hall, Christopher D., 1991, “Renting Ideas,” Journal of Business. 64, 21-48.

Hart, Oliver D., and Bengt Holmström, 1987, "The Theory of Contracts," in Truman F. Bewley, editor, F., ed., Advances in Economic Theory: Fifth World Congress.

(Econometric Society Monographs series, no. 12.) New York: Cambridge University Press, pp. 71-155.

Hart, Oliver D., and John Moore, 1988, "Incomplete Contracts and Renegotiation," Econometrica. 56, 755-785.

Holmström, Bengt, 1979, "Moral Hazard and Observability," Bell Journal of Economics. $10,74-91$. 
Holmström, Bengt, and John Roberts 1998, "The Boundaries of the Firm Revisited," Journal of Economic Perspectives. 12, 73-94.

Kamien, Morton, and Yair Tauman, 1986, "Fees versus Royalties and the Private Value of a Patent," Quarterly Journal of Economics. 101, 471-93.

Kaplan, Steven N., and Per Stromberg, 2000, "Financial Contracting Theory Meets the Real World: An Empirical Analysis of Venture Capital Contracts," Discussion Paper no. 2421, Centre for Economic Policy Research.

Katz, Michael L., and Carl Shapiro, 1985, "On the Licensing of Innovations," Rand Journal of Economics. 16, 504-520.

Joskow, Paul L., 1987, "Contract Duration and Relationship-Specific Investment," American Economic Review. 77, 168-185.

Lerner, Josh, and Robert P. Merges, 1998, "The Control of Technology Alliances: An Empirical Analysis of the Biotechnology Industry," Journal of Industrial Economics. (Special Issue on "Inside the Pin Factory: Empirical Studies Augmented by Manager Interviews.”) 46, 125-156. 


\section{Figure 1}

The evolution of Yahoo!'s homepage. The upper left page is from 1994; the upper right from 1995; the bottom left from 1997; and the bottom right from 1999. The source is Girotto and Rivkin [1999]. Copyright (C) 1999 by the President and Fellows of Harvard University. Reprinted with permission.

\section{Yahoo}

[ What's New? I What's Cool? I What's Popular? | A Random Link ]

\section{[ Gabaa I Upp I Search I Suggest I Add I Help. ]}

- Art itilyl [new]

B nsiness icksitil [new]

- Computers "ivitid [new]

- Economy i2 28 ? [new]

- Education iforgl [new]

- Environment and Nature "ate? [new]

- Environment and

- Events itisl [new]

- Government itirth

- Health (niss? [new]

- Lav ia?d! [new]

- Nevs (nizy) [new]

- Politics ifosl [new]

Reference

Regional Information 'susj! [new]

- Science (nizopl [new

- Social Science it/5i [new]

- Society and Colture i $7 \rightarrow ?$ [new]

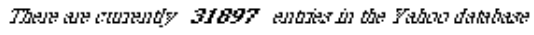

Some Other General Internet Directories:

[WWW Virtual Library * EINet Galaxy* University of Michigan Clearing house ]

[ GNN - Whole Intemet Catalog * Planet Earth * Yanoff's Connections ]

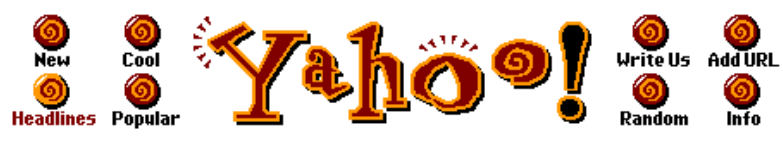

[ Text-Only Yahoo | New Features and Changes to Yahoo! ]

\begin{tabular}{|c|c|}
\hline & Search options \\
\hline 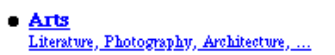 & 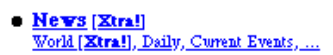 \\
\hline 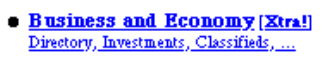 & 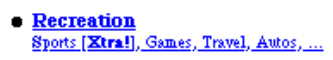 \\
\hline 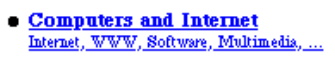 & $\begin{array}{l}\text { - Reference } \\
\underline{\text { Libraries, Dictionaries, Phone Numbers, .... }}\end{array}$ \\
\hline - $\frac{\text { Education }}{\underline{\text { Universities, }} \underline{\mathrm{K}-12}, \underline{\text { Cousses }}, \ldots}$ & - $\underline{\text { Regional }}_{\text {Countries, Regions, U.S.S. States, }, . . .}$ \\
\hline 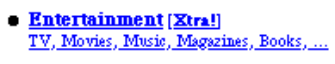 & - $\begin{array}{l}\text { Science } \\
\text { CS, Biology, Astronom } y, \text { Engineering, }, . . .\end{array}$ \\
\hline $\begin{array}{l}\text { - Government } \\
\text { Politics [Xtra!], Aggencies, Law, Military, }\end{array}$ & 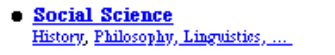 \\
\hline - $\begin{array}{l}\text { Health } \\
\text { Medicine, Dnugs, Diseases, Fitness, ... }\end{array}$ & 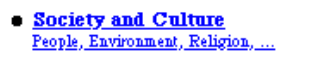 \\
\hline
\end{tabular}

Thanks to Netscape Communications for hard ware and network resources and other contributors

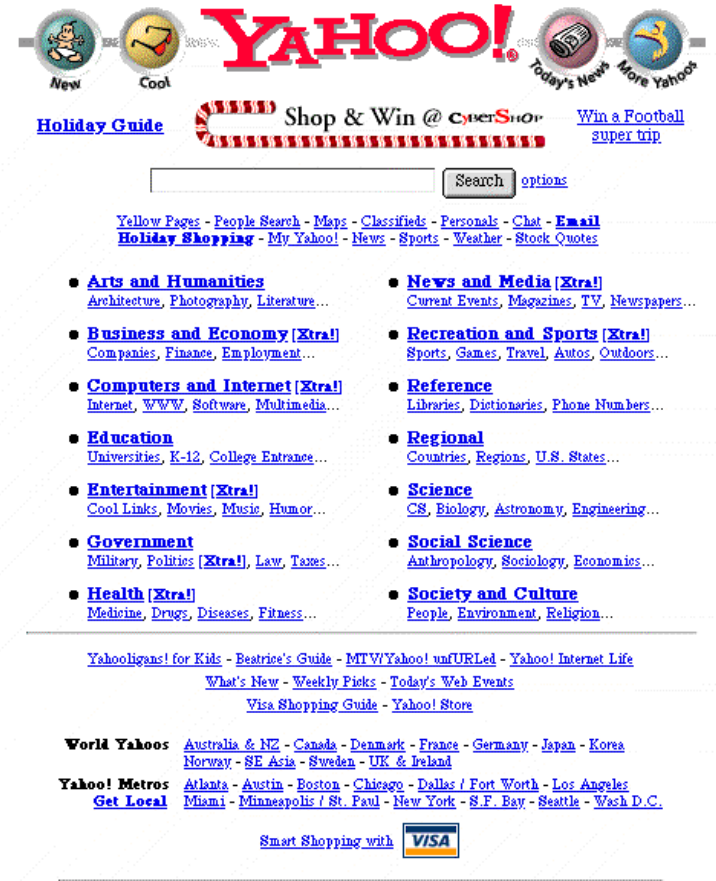

How to Suggest a Site - Compangly Info - Openiings at Yahoo! - Contributors - Yahoo! to Go

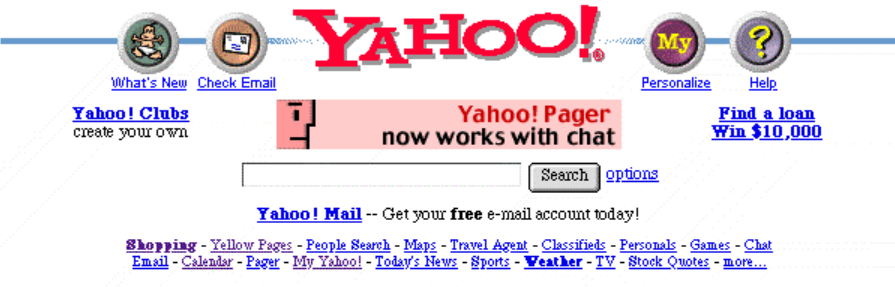

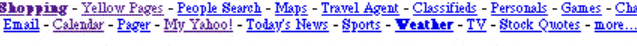

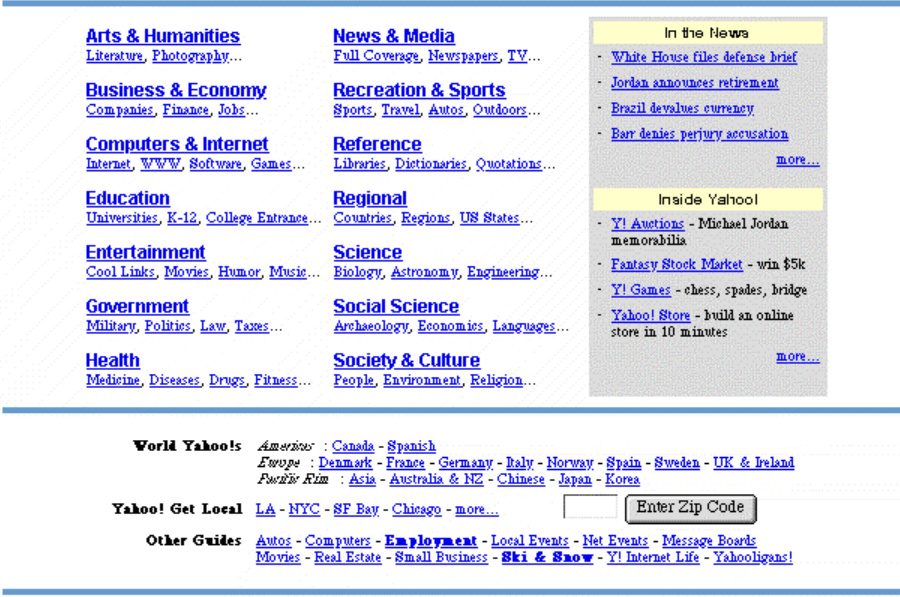

Yahoo! prefers VISA

How to Sugegst a Site - Company Info - Privacy Policy - Contributors - Openings at Yahool 
Table 1

Summary statistics. The sample consists of 106 alliances involving Internet portals between 1995 and 1999. Observations are summarized by the date of the agreement, the effort required of the portal and partner (cases where the portal is expected to make the greatest effort are coded as +1 , those where the partner is as -1 , and those where the effort is shared or not applicable are coded as 0 ), the traffic on the portal and the partner's Internet properties in the month before the signing of the contract, and the financial position of the portal and the partner in the quarter before the signing of the contract (in millions of dollars).

\begin{tabular}{|c|c|c|c|c|c|}
\hline \multicolumn{6}{|c|}{ Panel A: Distribution of Observations by Year } \\
\hline & 1995 & 1996 & 1997 & 1998 & 1999 \\
\hline Number of Contracts Signed in Year & 1 & 6 & 27 & 46 & 26 \\
\hline \multicolumn{6}{|c|}{ Panel B: Effort Required by Two Parties } \\
\hline & Mean & Median & Stan. Dev. & Minimum & Maximum \\
\hline Site development & -0.65 & -1 & 0.66 & -1 & 1 \\
\hline Maintenance and hosting & -0.58 & -1 & 0.69 & -1 & 1 \\
\hline Customer service & -0.56 & -1 & 0.54 & -1 & 1 \\
\hline Order fulfillment & -0.50 & -1 & 0.56 & -1 & 1 \\
\hline Billing & -0.46 & -1 & 0.59 & -1 & 1 \\
\hline Sum of five effort measures & -2.75 & -3 & 2.30 & -5 & 5 \\
\hline \multicolumn{6}{|c|}{ Panel C: Traffic on Internet Properties of Portal and Partner } \\
\hline & Mean & Median & Stan. Dev. & Minimum & Maximum \\
\hline reach of portal & $29.5 \%$ & $31.2 \%$ & $19.8 \%$ & $0.8 \%$ & $67.1 \%$ \\
\hline reach of partner & $4.9 \%$ & $1.5 \%$ & $10.2 \%$ & $0.2 \%$ & $55.3 \%$ \\
\hline Days per viewer-month for portal & 3.30 & 3.21 & 1.36 & 1.10 & 6.50 \\
\hline Days per viewer-month for partner & 1.67 & 1.46 & 0.68 & 1.00 & 4.50 \\
\hline Minutes per viewer-month for portal & 19.34 & 14.10 & 15.67 & 4.20 & 73.90 \\
\hline Minutes per viewer-month for partner & 8.87 & 7.30 & 6.43 & 1.40 & 36.70 \\
\hline \multicolumn{6}{|c|}{ Panel D: Financial Position of Portal and Partner } \\
\hline & Mean & Median & Stan. Dev. & Minimum & Maximum \\
\hline Sales of portal & 953 & 30 & 2873 & 0 & 23978 \\
\hline Sales of partner & 759 & 4 & 4276 & 0 & 37903 \\
\hline Net income of portal & 134 & -1 & 437 & -104 & 2284 \\
\hline Net income of partner & 39 & -3 & 257 & -433 & 1986 \\
\hline Cash of portal & 1606 & 174 & 4271 & 0 & 21761 \\
\hline Cash of partner & 720 & 17 & 3327 & 0 & 24956 \\
\hline Shareholders' equity of portal & 2646 & 306 & 6621 & -1 & 37165 \\
\hline Shareholders' equity of partner & 1161 & 16 & 4346 & -8 & 24067 \\
\hline
\end{tabular}


Table 2

The allocation of ownership in portal alliances. The sample consists of 106 alliances involving Internet portals between 1995 and 1999. Observations are divided by the date of the agreement, the relative effort required of the portal and partner, the relative reach of the portal and the partner in the month before the signing of the contract, and the relative sales of the portal and the partner in the quarter before the signing of the contract. The table presents the ownership of the URL, servers, and customer data, as well as a composite consisting of the sum of all four measures. +1 denoted a case where the ownership was assigned to the portal, -1 those where it was assigned to the partner, and 0 intermediate cases. The rightmost column presents the test statistics from $\chi^{2}$-tests of the significance of these differences (F-tests in the case of the composite variable).

\begin{tabular}{|c|c|c|c|c|}
\hline \multicolumn{5}{|c|}{ "Panel A: Ownership of URL } \\
\hline & \multicolumn{3}{|c|}{ Average Ownership for Alliances When... } & \multirow{2}{*}{$\begin{array}{c}\text { Test } \\
\text { Statistic }\end{array}$} \\
\hline & False & Intermediate & True & \\
\hline Is this a late agreement? & 0.06 & 0.28 & 0.46 & 7.22 \\
\hline Is most effort required of portal? & -0.05 & 0.42 & 0.50 & $* * * 23.80$ \\
\hline Does portal have greater reach? & 0.33 & 0.06 & 0.29 & 2.66 \\
\hline Does portal have greater revenues? & 0.48 & 0.00 & 0.22 & 2.52 \\
\hline \multicolumn{5}{|c|}{ Panel B: Ownership of Server } \\
\hline & \multicolumn{3}{|c|}{ Average Ownership for Alliances When... } & \multirow{2}{*}{$\begin{array}{c}\text { Test } \\
\text { Statistic }\end{array}$} \\
\hline & False & Intermediate & True & \\
\hline Is this a late agreement? & -0.62 & -0.28 & -0.50 & 4.57 \\
\hline Is most effort required of portal? & -0.90 & -0.49 & 0.50 & $* * * 51.73$ \\
\hline Does portal have greater reach? & -0.33 & 0.39 & -0.46 & 2.47 \\
\hline Does portal have greater revenues? & -0.14 & -0.50 & -0.52 & *8.32 \\
\hline \multicolumn{5}{|c|}{ Panel C: Ownership of Customer Data } \\
\hline & \multicolumn{3}{|c|}{ Average Ownership for Alliances When... } & \multirow{2}{*}{$\begin{array}{c}\text { Test } \\
\text { Statistic }\end{array}$} \\
\hline & False & Intermediate & True & \\
\hline Is this a late agreement? & -0.38 & -0.17 & -0.23 & 3.44 \\
\hline Is most effort required of portal? & -0.61 & -0.05 & 0.00 & $* * * 34.00$ \\
\hline Does portal have greater reach? & 0.00 & -0.06 & -0.31 & 4.88 \\
\hline Does portal have greater revenues? & -0.19 & -0.33 & -0.27 & 1.02 \\
\hline \multicolumn{5}{|c|}{ Panel D: Sum of Three Ownership Measures } \\
\hline & \multicolumn{3}{|c|}{ Average Ownership for Alliances When... } & Test \\
\hline & False & Intermediate & True & Statistic \\
\hline Is this a late agreement? & -0.94 & -0.17 & -0.27 & $* 2.59$ \\
\hline Is most effort required of portal? & -1.56 & -0.12 & 1.00 & $* * * 32.61$ \\
\hline Does portal have greater reach? & 0.00 & -0.39 & -0.47 & 0.14 \\
\hline Does portal have greater revenues? & 0.14 & -0.83 & -0.57 & 1.91 \\
\hline
\end{tabular}

$*=$ Significant at the $10 \%$ confidence level; $* *=$ significant at the $5 \%$ confidence level; $* * *=$ significant at the $1 \%$ confidence level. 


\section{Table 3}

Ordered logit regression analyses of the allocation of ownership in portal alliances. The sample consists of 106 alliances involving Internet portals between 1995 and 1999. The dependent variable is the sum of measures of the ownership of the URL, servers, and customer data (+1 denoted a case where the ownership was assigned to the portal, -1 those where it was assigned to the partner, and 0 intermediate cases.) Independent variables include the year of the agreement, the relative effort required of the portal and partner after the alliance signing on five key dimensions (with those where the most effort is required of the portal coded as -5 and the most effort by the portal as +5 ), the relative reach of the portal and the partner in the month before the signing of the contract (in most regressions, +1 denoted a case where the portal has the greater reach, -1 those where the partner did, and 0 intermediate cases, though in one case the difference in the reach measures is used), and the relative sales of the portal and the partner in the quarter before the signing of the contract (in most regressions, +1 denoted a case where the portal has the greater sales, -1 those where the partner did, and 0 intermediate cases, though in one case the difference in the actual sales in billions of 1999 dollars is used). Two regressions include controls for the type of the agreement and the portals entering into the agreements (not reported). Heteroskedasticconsistent standard errors in brackets.

\begin{tabular}{|c|c|c|c|c|c|}
\hline Year of agreement & $\begin{array}{c}\text { Basic } \\
\text { specification } \\
* 0.39[0.21]\end{array}$ & \multicolumn{2}{|c|}{$\begin{array}{l}\text { Exploring robustness to } \\
\text { alternative measures }\end{array}$} & $\begin{array}{l}\text { Controlling for } \\
\text { deal type } \\
* * 0.42[0.18]\end{array}$ & $\begin{array}{r}\text { Controlling for } \\
\text { deal type \& portal } \\
0.33[0.21\end{array}$ \\
\hline Relative effort required after alliance signing & $* * * 0.65[0.06]$ & $* * * 0.69[0.09]$ & $* * * 0.58[0.10]$ & $* * * 0.57[0.07]$ & $* * * 0.45[0.07]$ \\
\hline Does the portal have greater reach? & $0.18[0.44]$ & $-0.17[0.66]$ & & $0.20[0.37]$ & $0.28[0.31]$ \\
\hline Does the portal have greater sales? & $-0.19[0.31]$ & & $-0.08[0.42]$ & $-0.19[0.37]$ & $0.24[0.40]$ \\
\hline Difference between portal and partner's sales & & $-0.01[0.03]^{1}$ & & & \\
\hline Did the alliance promote content? & & & & $-0.34[0.68]$ & $-0.66[0.66]$ \\
\hline Number of observations & 106 & 87 & 64 & 102 & 102 \\
\hline Log likelihood & -162.62 & -129.73 & -98.23 & -155.25 & -148.87 \\
\hline Pseudo $\mathrm{R}^{2}$ & 0.15 & 0.17 & 0.14 & 0.16 & 0.19 \\
\hline
\end{tabular}

\footnotetext{
$*=$ Significant at the $10 \%$ confidence level; $* *=$ significant at the $5 \%$ confidence level; $* * *=$ significant at the $1 \%$ confidence level.
}

${ }^{1}$ coefficient and standard error multiplied by $10^{-4}$ 
Table 4

The allocation of control in portal alliances. The sample consists of 106 alliances involving Internet portals between 1995 and 1999. Observations are divided by the date of the agreement, the relative effort required of the portal and partner, the relative reach of the portal and the partner in the month before the signing of the contract, and the relative sales of the portal and the partner in the quarter before the signing of the contract. The table presents several measures of allocation of control: whether one party's line of business is specified, the material must be explicitly approved by one party, the material must conform to one party's standard, the "look and feel" of the material is determined by one party, one party must mention the other in its advertising, and the advertising copy must be approved by one party. $(+1$ denoted a case where control was assigned to the portal, -1 those where it was assigned to the partner, and 0 intermediate cases.) The table also reports the presence of a variety of control rights that the portal may exercise over the partner: that the partner must optimize the site for the portal's software or employ the portal's software, that the partner must use frames or other navigational devices, that a good faith effort must be made to return users to the portal, and that the portal receives equity in and board observers rights at the partner. ( +1 denoted a case where control was assigned to the portal and 0 where it was not.) The table also presents a composite consisting of the sum of all 12 measures. The rightmost column presents the test statistics from $\chi^{2}$-tests of the significance of these differences (F-tests in the case of the composite variable).

\begin{tabular}{|c|c|c|c|c|}
\hline \multicolumn{5}{|c|}{ Panel A: Specification of Line-of-Business } \\
\hline & \multicolumn{3}{|c|}{ Average Control for Alliances When... } & \multirow{2}{*}{$\begin{array}{c}\text { Test } \\
\text { Statistic }\end{array}$} \\
\hline & False & Intermediate & True & \\
\hline Is this a late agreement? & 0.21 & 0.20 & 0.50 & $* * 8.68$ \\
\hline Is most effort required of portal? & 0.30 & 0.33 & 0.14 & 2.79 \\
\hline Does portal have greater reach? & 0.00 & 0.00 & 0.35 & $* * * 10.02$ \\
\hline Does portal have greater revenues? & 0.05 & 0.33 & 0.33 & $* * 6.32$ \\
\hline \multicolumn{5}{|c|}{ Panel B: Explicit Approval of Content } \\
\hline & \multicolumn{3}{|c|}{ Average Control for Alliances When... } & Test \\
\hline & False & Intermediate & True & Statistic \\
\hline Is this a late agreement? & 0.24 & 0.22 & 0.23 & 0.04 \\
\hline Is most effort required of portal? & 0.12 & 0.33 & 0.23 & $* 4.97$ \\
\hline Does portal have greater reach? & 0.33 & 0.22 & 0.23 & 0.20 \\
\hline Does portal have greater revenues? & 0.19 & 0.17 & 0.24 & 0.37 \\
\hline \multicolumn{5}{|c|}{ Panel C: Conformance to Posted Standards } \\
\hline & \multicolumn{3}{|c|}{ Average Control for Alliances When... } & Test \\
\hline & False & Intermediate & True & Statistic \\
\hline Is this a late agreement? & 0.24 & 0.14 & 0.32 & 2.48 \\
\hline Is most effort required of portal? & 0.23 & 0.29 & 0.05 & 5.80 \\
\hline Does portal have greater reach? & 0.00 & 0.00 & 0.27 & 7.63 \\
\hline Does portal have greater revenues? & -0.10 & 0.33 & 0.29 & $* * * 16.33$ \\
\hline \multicolumn{5}{|c|}{ Panel D: Determination of Site's "Look and Feel" } \\
\hline & \multicolumn{3}{|c|}{ Average Control for Alliances When... } & Test \\
\hline & False & Intermediate & True & Statistic \\
\hline Is this a late agreement? & 0.06 & 0.22 & -0.08 & 5.43 \\
\hline Is most effort required of portal? & -0.12 & 0.09 & 0.50 & $* * 10.38$ \\
\hline Does portal have greater reach? & 0.00 & 0.11 & 0.09 & 0.27 \\
\hline Does portal have greater revenues? & 0.57 & 0.17 & -0.04 & $* * 11.61$ \\
\hline \multicolumn{5}{|c|}{ Panel E: Requirement to Mention Other Party in Advertising } \\
\hline & \multicolumn{3}{|c|}{ Average Control for Alliances When... } & Test \\
\hline & False & Intermediate & True & Statistic \\
\hline Is this a late agreement? & 0.24 & 0.13 & 0.23 & 1.80 \\
\hline Is most effort required of portal? & 0.24 & 0.23 & 0.00 & $* * 6.47$ \\
\hline Does portal have greater reach? & 0.00 & 0.11 & 0.21 & 1.70 \\
\hline Does portal have greater revenues? & 0.05 & 0.00 & 0.24 & $* 5.51$ \\
\hline
\end{tabular}




\begin{tabular}{|c|c|c|c|c|}
\hline \multicolumn{5}{|c|}{ Panel F: Approval of Advertising Copy } \\
\hline & \multicolumn{3}{|c|}{ Average Control for Alliances When... } & \multirow{2}{*}{$\begin{array}{c}\text { Test } \\
\text { Statistic }\end{array}$} \\
\hline & False & Intermediate & True & \\
\hline Is this a late agreement? & 0.06 & 0.02 & 0.00 & 1.98 \\
\hline Is most effort required of portal? & 0.05 & 0.02 & 0.00 & 1.31 \\
\hline Does portal have greater reach? & 0.00 & 0.06 & 0.02 & 0.64 \\
\hline Does portal have greater revenues? & 0.00 & 0.00 & 0.04 & 1.06 \\
\hline \multicolumn{5}{|c|}{ Panel G: Partner Required to Optimize Site for Viewing } \\
\hline & \multicolumn{3}{|c|}{ Average Control for Alliances When... } & Test \\
\hline & False & Intermediate & True & Statistic \\
\hline Is this a late agreement? & 0.18 & 0.17 & 0.15 & 0.06 \\
\hline Is most effort required of portal? & 0.12 & 0.28 & 0.05 & $* * 6.72$ \\
\hline Does portal have greater reach? & 0.33 & 0.11 & 0.18 & 1.04 \\
\hline Does portal have greater revenues? & 0.00 & 0.00 & 0.23 & $* * 7.41$ \\
\hline \multicolumn{5}{|c|}{ Panel H: Partner Required to Use Certain Software } \\
\hline & \multicolumn{3}{|c|}{ Average Control for Alliances When... } & Test \\
\hline & False & Intermediate & True & Statistic \\
\hline Is this a late agreement? & 0.24 & 0.07 & 0.12 & $* 5.02$ \\
\hline Is most effort required of portal? & 0.10 & 0.19 & 0.09 & 1.84 \\
\hline Does portal have greater reach? & 0.00 & 0.17 & 0.13 & 0.65 \\
\hline Does portal have greater revenues? & 0.10 & 0.00 & 0.15 & 1.43 \\
\hline \multicolumn{5}{|c|}{ Panel I: Partner Required to Use Frames or Other Navigational Devices } \\
\hline & \multicolumn{3}{|c|}{ Average Control for Alliances When... } & Test \\
\hline & False & Intermediate & True & Statistic \\
\hline Is this a late agreement? & 0.26 & 0.24 & 0.38 & 1.81 \\
\hline Is most effort required of portal? & 0.37 & 0.19 & 0.32 & 3.51 \\
\hline Does portal have greater reach? & 0.33 & 0.17 & 0.31 & 1.45 \\
\hline Does portal have greater revenues? & 0.24 & 0.50 & 0.28 & 1.61 \\
\hline \multicolumn{5}{|c|}{ Panel J: Partner Required to Try to Return Users } \\
\hline & \multicolumn{3}{|c|}{ Average Control for Alliances When... } & Test \\
\hline & False & Intermediate & True & Statistic \\
\hline Is this a late agreement? & 0.24 & 0.09 & 0.27 & $* 4.82$ \\
\hline Is most effort required of portal? & 0.24 & 0.21 & 0.00 & $* * 6.23$ \\
\hline Does portal have greater reach? & 0.00 & 0.00 & 0.22 & *5.72 \\
\hline Does portal have greater revenues? & 0.00 & 0.17 & 0.23 & $* 5.86$ \\
\hline \multicolumn{5}{|c|}{ Panel K: Portal Receives Equity in Partner } \\
\hline & \multicolumn{3}{|c|}{ Average Control for Alliances When... } & Test \\
\hline & False & Intermediate & True & Statistic \\
\hline Is this a late agreement? & 0.06 & 0.11 & 0.20 & 2.86 \\
\hline Is most effort required of portal? & 0.10 & 0.14 & 0.09 & 0.57 \\
\hline Does portal have greater reach? & 0.33 & 0.00 & 0.13 & 3.97 \\
\hline Does portal have greater revenues? & 0.00 & 0.33 & 0.13 & *5.71 \\
\hline \multicolumn{5}{|c|}{ Panel L: Portal Receives Board Observation Rights } \\
\hline & \multicolumn{3}{|c|}{ Average Control for Alliances When... } & Test \\
\hline & False & Intermediate & True & Statistic \\
\hline Is this a late agreement? & 0.03 & 0.00 & 0.00 & 2.11 \\
\hline Is most effort required of portal? & 0.00 & 0.02 & 0.00 & 1.51 \\
\hline Does portal have greater reach? & 0.00 & 0.00 & 0.01 & 0.25 \\
\hline \multirow{2}{*}{\multicolumn{5}{|c|}{$\begin{array}{c}\text { Does portal have greater revenues? } \\
\text { Panel M: Sum of Twelve Control Measures }\end{array}$}} \\
\hline & & & & \\
\hline & \multicolumn{3}{|c|}{ Average Control for Alliances When... } & \\
\hline & False & Intermediate & True & Statistic \\
\hline Is this a late agreement? & 2.00 & 1.57 & 2.29 & 1.57 \\
\hline Is most effort required of portal? & 1.69 & 2.34 & 1.32 & *3.06 \\
\hline Does portal have greater reach? & 1.00 & 1.27 & 1.68 & $* * 3.55$ \\
\hline Does portal have greater revenues? & 0.95 & 2.00 & 2.12 & $* * 4.04$ \\
\hline
\end{tabular}


$*=$ Significant at the $10 \%$ confidence level; $* *=$ significant at the $5 \%$ confidence level; $* * *=$ significant at the $1 \%$ confidence level. 


\section{Table 5}

Ordered logit regression analyses of the allocation of control in portal alliances. The sample consists of 106 alliances involving Internet portals between 1995 and 1999. The dependent variable is the sum of twelve measures of the allocation of control $(+1$ denoted a case where the control was assigned to the portal, -1 those where it was assigned to the partner, and 0 intermediate cases.) Independent variables include the year of the agreement, the relative effort required of the portal and partner after the alliance signing on five key dimensions (with those where the most effort is required of the portal coded as -5 and the most effort by the portal as +5 ), the relative reach of the portal and the partner in the month before the signing of the contract (in most regressions, +1 denoted a case where the portal has the greater reach, -1 those where the partner did, and 0 intermediate cases, though in one case each the difference in the reach measures, the mean days spent in each month on the site per Internet user, and the mean monthly minutes per Internet user are used), and the relative sales of the portal and the partner in the quarter before the signing of the contract ( +1 denoted a case where the portal has the greater sales, -1 those where the partner did, and 0 intermediate cases). One regression includes controls for the type of the agreement. Heteroskedastic-consistent standard errors in brackets.

\begin{tabular}{|c|c|c|c|c|c|}
\hline \multirow[b]{2}{*}{ Year of agreement } & \multirow{2}{*}{$\begin{array}{c}\text { Basic } \\
\text { specification } \\
0.07[0.18]\end{array}$} & \multicolumn{3}{|c|}{$\begin{array}{c}\text { Exploring robustness to } \\
\text { alternative measures }\end{array}$} & \multirow{2}{*}{$\begin{array}{c}\text { Controlling for } \\
\text { deal type } \\
0.12[0.19]\end{array}$} \\
\hline & & $0.10[0.38]$ & $-0.02[0.38]$ & $0.03[0.22]$ & \\
\hline Relative effort required after alliance signing & $0.03[0.09]$ & $0.11[0.07]$ & $0.09[0.08]$ & $0.07[0.09]$ & $0.02[0.08]$ \\
\hline Does the portal have greater reach? & $* * 0.73[0.26]$ & & & & $* * * 0.63[0.18]$ \\
\hline Difference between portal and partner's reach & & $* * 2.62[1.06]$ & & & \\
\hline Difference between portal and partner's daily usage & & & $* * * 0.52[0.18]$ & & \\
\hline Difference between portal and partner's total usage & & & & $* 0.03[0.02]$ & \\
\hline Does the portal have greater sales? & $* 0.50[0.28]$ & $0.35[0.22]$ & $0.34[0.22]$ & $* * 0.49[0.26]$ & $0.46[0.30]$ \\
\hline Did the alliance promote content? & & & & & $0.73[0.75]$ \\
\hline Did the alliance promote product sales? & & & & & $0.58[0.66]$ \\
\hline Did the alliance involve a service agreement? & & & & & $0.62[0.83]$ \\
\hline Number of observations & 99 & 62 & 62 & 62 & 96 \\
\hline Log likelihood & -176.90 & -107.37 & -106.99 & -109.43 & -171.57 \\
\hline Pseudo $\mathrm{R}^{2}$ & 0.03 & 0.05 & 0.05 & 0.03 & 0.03 \\
\hline
\end{tabular}

\footnotetext{
$*=$ Significant at the $10 \%$ confidence level; $* *=$ significant at the $5 \%$ confidence level; $* * *=$ significant at the $1 \%$ confidence level.
} 
Table 6

The contractual completeness of portal alliances. The sample consists of 106 alliances involving Internet portals between 1995 and 1999. Observations are divided by the date of the agreement, the relative effort required of the portal and partner, the relative reach of the portal and the partner in the month before the signing of the contract, and the relative sales of the portal and the partner in the quarter before the signing of the contract. The table presents several measures of contractual completeness. Panels A through $\mathrm{F}$ report on the presence of provisions relating to market success: minimum numbers of impressions, targeted impressions, click-throughs, revenues, and new customers. Panels G through $\mathrm{K}$ report on the presence of provisions relating to technological success: speed, uptime, customer service, and competitive ranking by third parties. +1 denoted a case where this contractual element was present and 0 a case where it was absent. The table also presents composite consisting of the sum of all market and technical measures. The rightmost column presents the test statistics from $\chi^{2}$-tests of the significance of these differences (F-tests in the case of the composite variables).

\begin{tabular}{|c|c|c|c|c|}
\hline \multicolumn{5}{|c|}{ Panel A: Minimum Number of Impressions } \\
\hline & \multicolumn{3}{|c|}{ Average Completeness for Alliances When... } & \multirow{2}{*}{$\begin{array}{c}\text { Test } \\
\text { Statistic }\end{array}$} \\
\hline & False & Intermediate & True & \\
\hline Is this a late agreement? & 0.71 & 0.59 & 0.77 & 2.79 \\
\hline Is most effort required of portal? & 0.80 & 0.58 & 0.59 & $* 5.52$ \\
\hline Does portal have greater reach? & 0.33 & 0.56 & 0.71 & 3.09 \\
\hline Does portal have greater revenues? & 0.52 & 0.67 & 0.71 & 2.57 \\
\hline \multicolumn{5}{|c|}{ Panel B: Minimum Number of Targeted Impressions } \\
\hline & \multicolumn{3}{|c|}{ Average Completeness for Alliances When... } & Test \\
\hline & False & Intermediate & True & Statistic \\
\hline Is this a late agreement? & 0.09 & 0.09 & 0.08 & 0.03 \\
\hline Is most effort required of portal? & 0.10 & 0.09 & 0.05 & 0.56 \\
\hline Does portal have greater reach? & 0.00 & 0.22 & 0.06 & *5.39 \\
\hline Does portal have greater revenues? & 0.10 & 0.00 & 0.09 & 0.60 \\
\hline \multicolumn{5}{|c|}{ Panel C: Minimum Number of Click-Throughs } \\
\hline & \multicolumn{3}{|c|}{ Average Completeness for Alliances When... } & \multirow{2}{*}{$\begin{array}{c}\text { Test } \\
\text { Statistic }\end{array}$} \\
\hline & False & Intermediate & True & \\
\hline Is this a late agreement? & 0.03 & 0.04 & 0.08 & 0.76 \\
\hline Is most effort required of portal? & 0.05 & 0.07 & 0.00 & 1.58 \\
\hline Does portal have greater reach? & 0.33 & 0.06 & 0.04 & *3.98 \\
\hline Does portal have greater revenues? & 0.05 & 0.00 & 0.05 & 0.32 \\
\hline \multicolumn{5}{|c|}{ Panel D: Minimum Revenue Targets } \\
\hline & \multicolumn{3}{|c|}{ Average Completeness for Alliances When... } & \multirow{6}{*}{\begin{aligned} & \multicolumn{1}{c}{ Test } \\
& Statistic \\
&$* * 8.43 \\
& 2.32 \\
& 1.70 \\
& 0.10\end{aligned}$} \\
\hline & False & Intermediate & True & \\
\hline Is this a late agreement? & 0.26 & 0.04 & 0.12 & \\
\hline Is most effort required of portal? & 0.20 & 0.09 & 0.09 & \\
\hline Does portal have greater reach? & 0.00 & 0.06 & 0.15 & \\
\hline Does portal have greater revenues? & 0.14 & 0.17 & 0.13 & \\
\hline \multicolumn{5}{|c|}{ Panel E: Minimum Number of New Customers } \\
\hline & \multicolumn{3}{|c|}{ Average Completeness for Alliances When... } & Test \\
\hline & False & Intermediate & True & Statistic \\
\hline Is this a late agreement? & 0.09 & 0.00 & 0.00 & $* * 6.54$ \\
\hline Is most effort required of portal? & 0.02 & 0.02 & 0.05 & 0.30 \\
\hline Does portal have greater reach? & 0.00 & 0.06 & 0.02 & 0.64 \\
\hline Does portal have greater revenues? & 0.05 & 0.00 & 0.03 & 0.49 \\
\hline
\end{tabular}




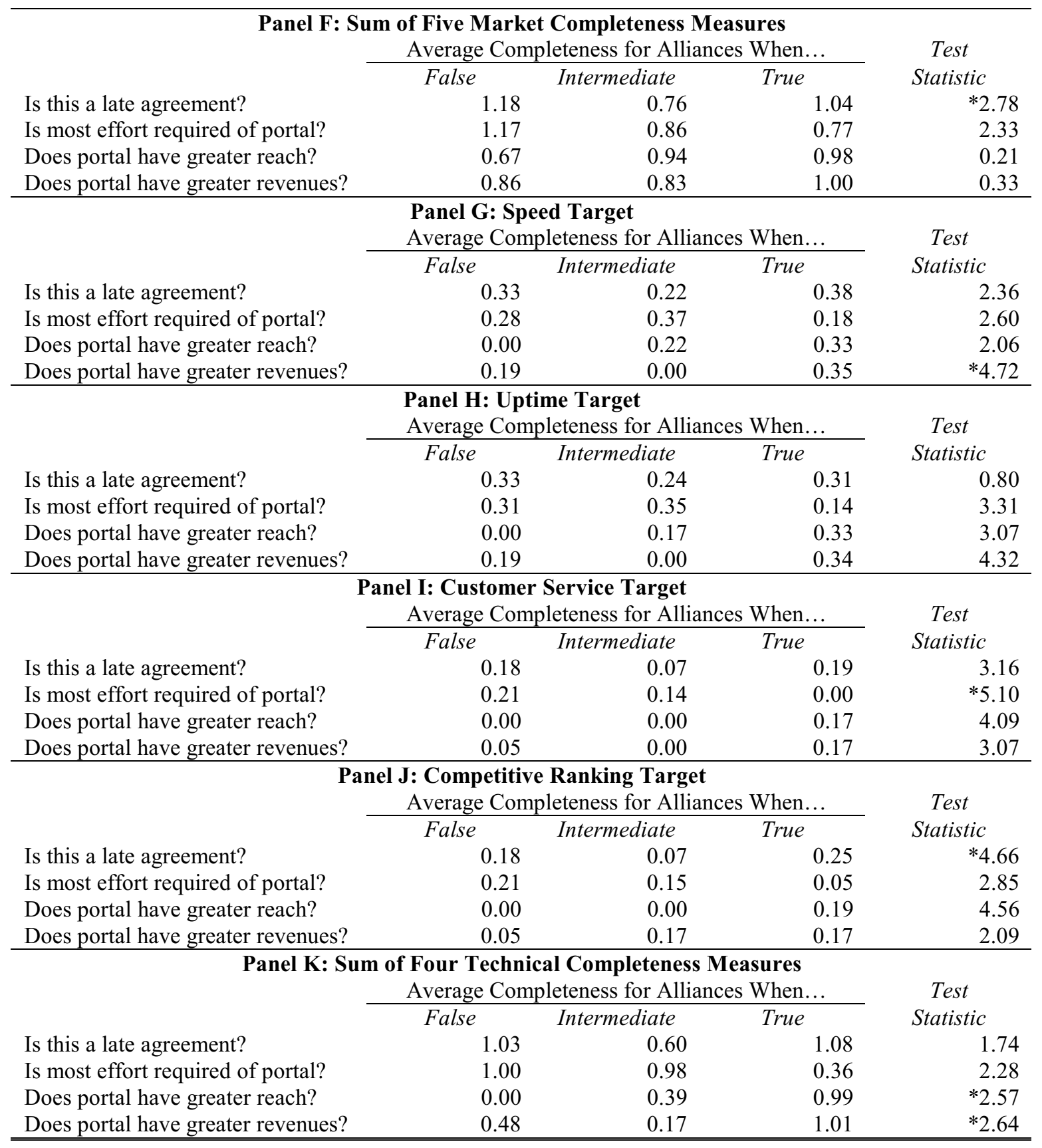

$*=$ Significant at the $10 \%$ confidence level; $* *=$ significant at the $5 \%$ confidence level; $* * *=$ significant at the $1 \%$ confidence level. 


\section{Table 7}

Ordered logit regression analyses of the contractual completeness in portal alliances. The sample consists of 106 alliances involving Internet portals between 1995 and 1999. The dependent variables are the sums of five measures of the completeness of the contract relating to product market performance $(+1$ denoted a case where this contractual element was present and 0 a case where it was absent) and four relating to technical performance. Independent variables include the year of the agreement, the relative effort required of the portal and partner after the alliance signing on five key dimensions (with those where the most effort is required of the portal coded as -5 and the most effort by the portal as +5 ), the relative reach of the portal and the partner in the month before the signing of the contract (in most regressions, +1 denoted a case where the portal has the greater reach, -1 those where the partner did, and 0 intermediate cases, though in one case the difference in the mean monthly minutes per Internet user is used), and the relative sales of the portal and the partner in the quarter before the signing of the contract ( +1 denoted a case where the portal has the greater sales, -1 those where the partner did, and 0 intermediate cases). Two regressions include controls for the type of the agreement and the portals entering into the agreements (not reported). Heteroskedastic-consistent standard errors in brackets.

\begin{tabular}{|c|c|c|c|c|c|}
\hline \multirow[b]{4}{*}{ Year of agreement } & \multicolumn{5}{|c|}{ Dependent Variable: } \\
\hline & \multicolumn{2}{|c|}{ Market Completeness } & \multicolumn{3}{|c|}{ Technical Completeness } \\
\hline & $\begin{array}{c}\text { Basic } \\
\text { specification }\end{array}$ & $\begin{array}{c}\text { Controlling for } \\
\text { deal type \& portal }\end{array}$ & $\begin{array}{c}\text { Basic } \\
\text { specification }\end{array}$ & $\begin{array}{l}\text { Exploring } \\
\text { robustness }\end{array}$ & $\begin{array}{c}\text { Controlling for } \\
\text { deal type \& portal }\end{array}$ \\
\hline & $-0.12[0.17]$ & $-0.13[0.22]$ & $0.04[0.21]$ & $-0.08[0.30]$ & $-0.02[0.29]$ \\
\hline Relative effort required after alliance signing & $-0.11[0.08]$ & $* * *_{-}-0.15[0.05]$ & $-0.17[0.12]$ & $*_{-} 0.16[0.10]$ & $0.03[0.10]$ \\
\hline Does the portal have greater reach? & $0.20[0.45]$ & $0.04[0.50]$ & $* * 1.00[0.41]$ & & $0.43[0.45]$ \\
\hline Difference between portal and partner's total usage & & & & $* * 0.06[0.02]$ & \\
\hline Does the portal have greater sales? & $0.17[0.37]$ & $0.17[0.33]$ & $0.40[0.39]$ & $0.23[0.61]$ & $0.28[0.70]$ \\
\hline Did the alliance promote content? & & $0.63[0.86]$ & & & $-0.90[0.58]$ \\
\hline Did the alliance promote product sales? & & $0.80[0.80]$ & & & $1.22[0.83]$ \\
\hline Did the alliance involve a service agreement? & & $-0.07[0.70]$ & & & $* * * 1.96[0.67]$ \\
\hline Number of observations & 106 & 102 & 102 & 61 & 99 \\
\hline Log likelihood & -121.92 & -111.02 & -111.82 & -58.59 & -87.94 \\
\hline Pseudo $\mathrm{R}^{2}$ & 0.02 & 0.07 & 0.05 & 0.06 & 0.22 \\
\hline
\end{tabular}

\footnotetext{
$*=$ Significant at the $10 \%$ confidence level; $* *=$ significant at the $5 \%$ confidence level; $* * *=$ significant at the $1 \%$ confidence level.
} 
Table 8

The exclusivity of portal alliances. The sample consists of 106 alliances involving Internet portals between 1995 and 1999. Observations are divided by the date of the agreement, the relative effort required of the portal and partner, the relative reach of the portal and the partner in the month before the signing of the contract, and the relative sales of the portal and the partner in the quarter before the signing of the contract. The table presents several measures of exclusivity of the alliance. Panel A through $\mathrm{H}$ report whether the portal is restricted from entering into any or more than a set number of agreements with competitors; from advertising competitors anywhere on the site, in specific areas, or on a continuous basis; from establishing any links to competitors' sites; and from granting the use of certain keywords to other firms, as well as the sum of these measures. Panels I through P report whether the partner is restricted from entering into any agreement with any competitor or agreements with competitors involving specific content; from advertising competitors anywhere on the site, in specific areas, or on a continuous basis; from promoting competitors in a more prominent manner; or from establishing any links to competitors' sites, as well as the sum of these measures. $(+1$ denoted a case where this exclusivity provision was present and 0 where it was absent.) The rightmost column presents the test statistics from $\chi^{2}$-tests of the significance of these differences (F-tests in the case of the composite variables).

\begin{tabular}{|c|c|c|c|c|}
\hline \multicolumn{5}{|c|}{ Panel A: Portal Cannot Establish Any Agreements with Competitors } \\
\hline & \multicolumn{3}{|c|}{ Average Exclusivity for Alliances When... } & Test \\
\hline & False & Intermediate & True & Statistic \\
\hline Is this a late agreement? & 0.47 & 0.39 & 0.35 & 1.02 \\
\hline Is most effort required of portal? & 0.49 & 0.30 & 0.45 & 3.27 \\
\hline Does portal have greater reach? & 0.33 & 0.39 & 0.41 & 0.10 \\
\hline Does portal have greater revenues? & 0.71 & 0.50 & 0.32 & $* * * 11.13$ \\
\hline \multicolumn{5}{|c|}{ Panel B: Portal Cannot Establish More than Set Number of Agreements with Competitors } \\
\hline & \multicolumn{3}{|c|}{ Average Exclusivity for Alliances When... } & Test \\
\hline & False & Intermediate & True & Statistic \\
\hline Is this a late agreement? & 0.56 & 0.46 & 0.46 & 0.93 \\
\hline Is most effort required of portal? & 0.54 & 0.42 & 0.55 & 1.50 \\
\hline Does portal have greater reach? & 0.33 & 0.61 & 0.47 & 1.47 \\
\hline Does portal have greater revenues? & 0.71 & 0.50 & 0.43 & $* 5.35$ \\
\hline \multicolumn{5}{|c|}{ Panel C: Portal Cannot Advertise Competitors } \\
\hline & \multicolumn{3}{|c|}{ Average Exclusivity for Alliances When... } & Test \\
\hline & False & Intermediate & True & Statistic \\
\hline Is this a late agreement? & 0.15 & 0.15 & 0.19 & 0.26 \\
\hline Is most effort required of portal? & 0.24 & 0.07 & 0.18 & $* 4.82$ \\
\hline Does portal have greater reach? & 0.33 & 0.06 & 0.18 & 2.30 \\
\hline Does portal have greater revenues? & 0.14 & 0.00 & 0.18 & 1.36 \\
\hline \multicolumn{5}{|c|}{ Panel D: Portal Cannot Advertise Competitors in Certain Areas } \\
\hline & \multicolumn{3}{|c|}{ Average Exclusivity for Alliances When... } & Test \\
\hline & False & Intermediate & True & Statistic \\
\hline Is this a late agreement? & 0.41 & 0.41 & 0.46 & 0.19 \\
\hline Is most effort required of portal? & 0.61 & 0.28 & 0.36 & $* * * 9.82$ \\
\hline Does portal have greater reach? & 0.33 & 0.33 & 0.45 & 0.89 \\
\hline Does portal have greater revenues? & 0.38 & 0.67 & 0.42 & 1.62 \\
\hline \multicolumn{5}{|c|}{ Panel E: Portal Cannot Advertise Competitors on a Continuous Basis } \\
\hline & \multicolumn{3}{|c|}{ Average Exclusivity for Alliances When... } & Test \\
\hline & False & Intermediate & True & Statistic \\
\hline Is this a late agreement? & 0.18 & 0.17 & 0.27 & 1.10 \\
\hline Is most effort required of portal? & 0.27 & 0.12 & 0.23 & 3.20 \\
\hline Does portal have greater reach? & 0.33 & 0.17 & 0.20 & 0.45 \\
\hline Does portal have greater revenues? & 0.19 & 0.00 & 0.22 & 1.64 \\
\hline
\end{tabular}




\begin{tabular}{|c|c|c|c|c|}
\hline \multicolumn{5}{|c|}{ Panel F: Portal Cannot Link to Competitors } \\
\hline & \multicolumn{3}{|c|}{ Average Exclusivity for Alliances When... } & Test \\
\hline & False & Intermediate & True & Statistic \\
\hline Is this a late agreement? & 0.15 & 0.13 & 0.12 & 0.13 \\
\hline Is most effort required of portal? & 0.10 & 0.12 & 0.23 & 2.26 \\
\hline Does portal have greater reach? & 0.33 & 0.17 & 0.12 & 1.40 \\
\hline Does portal have greater revenues? & 0.24 & 0.00 & 0.11 & 3.20 \\
\hline \multicolumn{5}{|c|}{ Panel G: Portal Cannot Grant Competitors Use of Certain Keywords } \\
\hline & \multicolumn{3}{|c|}{ Average Exclusivity for Alliances When... } & Test \\
\hline & False & Intermediate & True & Statistic \\
\hline Is this a late agreement? & 0.29 & 0.24 & 0.27 & 0.31 \\
\hline Is most effort required of portal? & 0.37 & 0.23 & 0.14 & 4.25 \\
\hline Does portal have greater reach? & 0.00 & 0.06 & 0.32 & $* * 6.35$ \\
\hline Does portal have greater revenues? & 0.10 & 0.17 & 0.32 & 4.49 \\
\hline \multicolumn{5}{|c|}{ Panel H: Sum of Seven Portal Exclusivity Measures } \\
\hline & \multicolumn{3}{|c|}{ Average Exclusivity for Alliances When... } & Test \\
\hline & False & Intermediate & True & Statistic \\
\hline Is this a late agreement? & 2.26 & 2.02 & 2.08 & 0.17 \\
\hline Is most effort required of portal? & 2.61 & 1.72 & 1.95 & *2.53 \\
\hline Does portal have greater reach? & 1.33 & 2.11 & 2.14 & 0.27 \\
\hline Does portal have greater revenues? & 2.48 & 3.17 & 1.94 & 1.72 \\
\hline \multicolumn{5}{|c|}{ Panel I: Partner Cannot Establish Any Agreements with Competitors } \\
\hline & \multicolumn{3}{|c|}{ Average Exclusivity for Alliances When... } & Test \\
\hline & False & Intermediate & True & Statistic \\
\hline Is this a late agreement? & 0.12 & 0.04 & 0.08 & 1.54 \\
\hline Is most effort required of portal? & 0.07 & 0.09 & 0.05 & 0.48 \\
\hline Does portal have greater reach? & 0.67 & 0.00 & 0.07 & $* * * 16.52$ \\
\hline Does portal have greater revenues? & 0.10 & 0.17 & 0.06 & 1.00 \\
\hline \multicolumn{5}{|c|}{ Panel J: Partner Cannot Establish Certain Agreements with Competitors } \\
\hline & \multicolumn{3}{|c|}{ Average Exclusivity for Alliances When... } & \\
\hline & False & Intermediate & True & Statistic \\
\hline Is this a late agreement? & 0.21 & 0.04 & 0.23 & $* * 6.50$ \\
\hline Is most effort required of portal? & 0.17 & 0.16 & 0.05 & 2.12 \\
\hline Does portal have greater reach? & 0.67 & 0.00 & 0.18 & $* * * 9.86$ \\
\hline Does portal have greater revenues? & 0.14 & 0.17 & 0.14 & 0.03 \\
\hline \multicolumn{5}{|c|}{ Panel K: Partner Cannot Advertise Competitors } \\
\hline & \multicolumn{3}{|c|}{ Average Exclusivity for Alliances When... } & Test \\
\hline & False & Intermediate & True & Statistic \\
\hline Is this a late agreement? & 0.24 & 0.11 & 0.15 & 2.34 \\
\hline Is most effort required of portal? & 0.17 & 0.21 & 0.05 & 2.95 \\
\hline Does portal have greater reach? & 0.67 & 0.00 & 0.18 & $* * 9.31$ \\
\hline Does portal have greater revenues? & 0.09 & 0.17 & 0.18 & 0.83 \\
\hline \multicolumn{5}{|c|}{ Panel L: Partner Cannot Advertise Competitors in Certain Areas } \\
\hline & \multicolumn{3}{|c|}{ Average Exclusivity for Alliances When... } & Test \\
\hline & False & Intermediate & True & Statistic \\
\hline Is this a late agreement? & 0.26 & 0.22 & 0.27 & 0.34 \\
\hline Is most effort required of portal? & 0.24 & 0.28 & 0.18 & 0.74 \\
\hline Does portal have greater reach? & 0.67 & 0.00 & 0.28 & $* * * 9.35$ \\
\hline Does portal have greater revenues? & 0.10 & 0.17 & 0.29 & 3.65 \\
\hline \multicolumn{5}{|c|}{ Panel M: Partner Cannot Advertise Competitors on a Continuous Basis } \\
\hline & \multicolumn{3}{|c|}{ Average Exclusivity for Alliances When... } & Test \\
\hline & False & Intermediate & True & Statistic \\
\hline Is this a late agreement? & 0.24 & 0.11 & 0.15 & 2.34 \\
\hline Is most effort required of portal? & 0.17 & 0.21 & 0.05 & 2.95 \\
\hline Does portal have greater reach? & 0.67 & 0.00 & 0.18 & $* * 9.31$ \\
\hline Does portal have greater revenues? & 0.10 & 0.17 & 0.18 & 0.83 \\
\hline
\end{tabular}




\begin{tabular}{|c|c|c|c|c|}
\hline \multicolumn{5}{|c|}{ Panel N: Partner Must Promote Portal at Least as Prominently as Competitors } \\
\hline & \multicolumn{3}{|c|}{ Average Exclusivity for Alliances When... } & \multirow{2}{*}{$\begin{array}{c}\text { Test } \\
\text { Statistic }\end{array}$} \\
\hline & False & Intermediate & True & \\
\hline Is this a late agreement? & 0.15 & 0.07 & 0.15 & 1.87 \\
\hline Is most effort required of portal? & 0.10 & 0.12 & 0.14 & 0.22 \\
\hline Does portal have greater reach? & 0.00 & 0.11 & 0.12 & 0.40 \\
\hline Does portal have greater revenues? & 0.14 & 0.00 & 0.11 & 0.95 \\
\hline \multicolumn{5}{|c|}{ Panel O: Partner Cannot Link to Competitors } \\
\hline & \multicolumn{3}{|c|}{ Average Exclusivity for Alliances When... } & Test \\
\hline & False & Intermediate & True & Statistic \\
\hline Is this a late agreement? & 0.09 & 0.04 & 0.19 & 4.33 \\
\hline Is most effort required of portal? & 0.07 & 0.14 & 0.05 & 1.86 \\
\hline Does portal have greater reach? & 0.33 & 0.00 & 0.11 & 4.01 \\
\hline Does portal have greater revenues? & 0.00 & 0.00 & 0.13 & 3.77 \\
\hline \multicolumn{5}{|c|}{ Panel P: Sum of Seven Partner Exclusivity Measures } \\
\hline & \multicolumn{3}{|c|}{ Average Exclusivity for Alliances When... } & Test \\
\hline & False & Intermediate & True & Statistic \\
\hline Is this a late agreement? & 1.35 & 0.67 & 1.31 & 1.81 \\
\hline Is most effort required of portal? & 1.05 & 1.26 & 0.64 & 0.87 \\
\hline Does portal have greater reach? & 4.33 & 0.11 & 1.13 & $* * * 8.78$ \\
\hline Does portal have greater revenues? & 0.67 & 0.83 & 1.16 & 0.69 \\
\hline
\end{tabular}

$*=$ Significant at the $10 \%$ confidence level; $* *=$ significant at the $5 \%$ confidence level; $* * *=$ significant at the $1 \%$ confidence level. 


\section{Table 9}

Ordered logit regression analyses of the exclusivity of portal alliances. The sample consists of 106 alliances involving Internet portals between 1995 and 1999. The dependent variables are the sums of seven measures of the exclusivity of the alliance relating to the portal $(+1$ denoted a case where an exclusivity provision was present and 0 a case where it was absent) and seven relating to the partner. Independent variables include the year of the agreement, the relative effort required of the portal and partner after the alliance signing on five key dimensions (with those where the most effort is required of the portal coded as -5 and the most effort by the portal as +5$)$, the relative reach of the portal and the partner in the month before the signing of the contract $(+1$ denoted a case where the portal has the greater reach, -1 those where the partner did, and 0 intermediate cases), and the relative sales of the portal and the partner in the quarter before the signing of the contract $(+1$ denoted a case where the portal has the greater sales, -1 those where the partner did, and 0 intermediate cases). In the rightmost regression the independent variable for relative reach described above is replaced with two dummy variables indicating whether the portal has greater reach $(+1$ if the portal has greater reach and 0 otherwise) or the partner has greater reach $(+1$ if the partner has greater reach and 0 otherwise). Two regressions include controls for the type of the agreement and the portals entering into the agreements (not reported). Heteroskedastic-consistent standard errors in brackets.

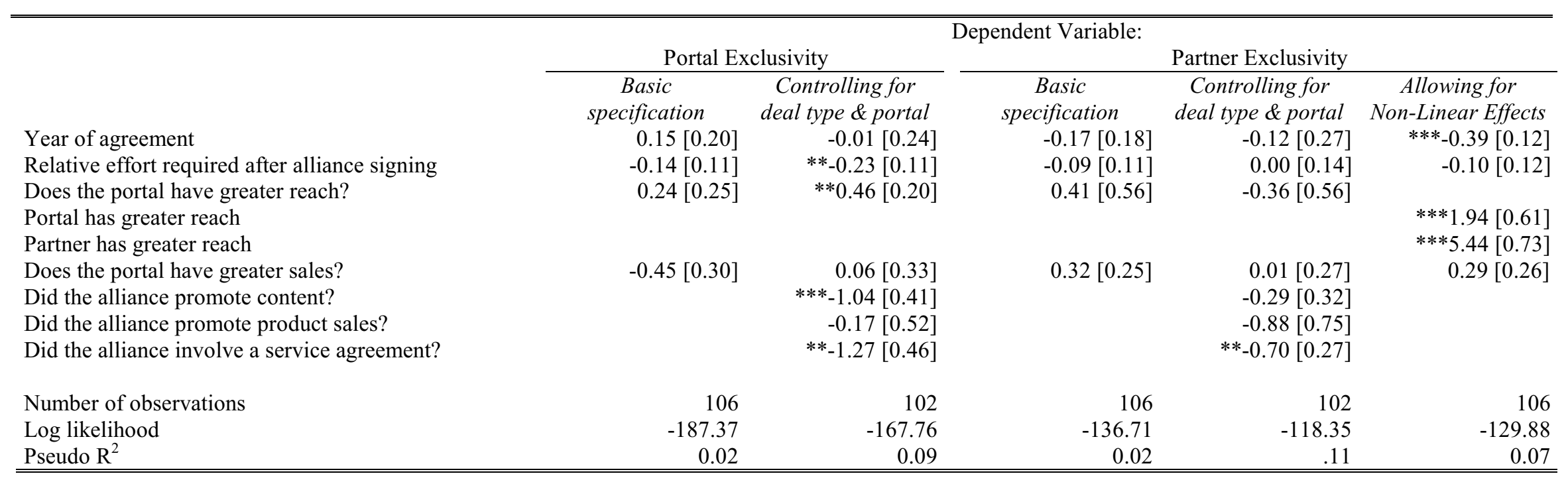

$*=$ Significant at the $10 \%$ confidence level; $* *=$ significant at the $5 \%$ confidence level; $* * *=$ significant at the $1 \%$ confidence level. 


\section{Table 10}

The payment structure in portal alliances. The sample consists of 106 alliances involving Internet portals between 1995 and 1999. Observations are divided by the date of the agreement, the relative effort required of the portal and partner, the relative reach of the portal and the partner in the month before the signing of the contract, and the relative sales of the portal and the partner in the quarter before the signing of the contract. The table presents several measures of payment structure in the alliance: whether the payment was exclusively a fixed fee, or based on product sales, gross margins, new customers and/or subscribers, or advertising revenues. +1 denoted a case where this element is present and 0 where it was absent. The rightmost column presents the test statistics from $\chi^{2}$-tests of the significance of these differences.

\begin{tabular}{|c|c|c|c|c|}
\hline \multicolumn{5}{|c|}{ Panel A: Fixed Payment Only } \\
\hline & \multicolumn{3}{|c|}{ Average for Alliances When... } & \multirow{2}{*}{$\begin{array}{c}\text { Test } \\
\text { Statistic }\end{array}$} \\
\hline & False & Intermediate & True & \\
\hline Is this a late agreement? & 0.21 & 0.39 & 0.42 & 4.07 \\
\hline Is most effort required of portal? & 0.37 & 0.30 & 0.36 & 0.45 \\
\hline Does portal have greater reach? & 0.00 & 0.22 & 0.38 & 3.16 \\
\hline Does portal have greater revenues? & 0.29 & 0.17 & 0.37 & 1.34 \\
\hline \multicolumn{5}{|c|}{ Panel B: Payment Based on Product Sales } \\
\hline & \multicolumn{3}{|c|}{ Average for Alliances When... } & Test \\
\hline & False & Intermediate & True & Statistic \\
\hline Is this a late agreement? & 0.29 & 0.26 & 0.35 & 0.58 \\
\hline Is most effort required of portal? & 0.44 & 0.21 & 0.18 & **6.99 \\
\hline Does portal have greater reach? & 0.33 & 0.22 & 0.31 & 0.53 \\
\hline Does portal have greater revenues? & 0.24 & 0.33 & 0.30 & 0.40 \\
\hline \multicolumn{5}{|c|}{ Panel C: Payment Based on Gross Margin } \\
\hline & \multicolumn{3}{|c|}{ Average for Alliances When... } & Test \\
\hline & False & Intermediate & True & Statistic \\
\hline Is this a late agreement? & 0.06 & 0.00 & 0.00 & 4.32 \\
\hline Is most effort required of portal? & 0.02 & 0.02 & 0.00 & 0.53 \\
\hline Does portal have greater reach? & 0.00 & 0.00 & 0.02 & 0.50 \\
\hline Does portal have greater revenues? & 0.00 & 0.00 & 0.03 & 0.70 \\
\hline
\end{tabular}

Panel D: Payment Based on New Customers and/or Subscribers

\begin{tabular}{lccrr}
\hline \multicolumn{1}{c}{ Panel D: Payment Based on New Customers and/or Subscribers } & & Test \\
& \multicolumn{2}{c}{ Average for Alliances When... } & Statistic \\
\cline { 2 - 3 } & False & Intermediate & True & \\
Is this a late agreement? & 0.09 & 0.13 & 0.04 & 1.67 \\
Is most effort required of portal? & 0.20 & 0.02 & 0.05 & $* * .03$ \\
Does portal have greater reach? & 0.00 & 0.06 & 0.11 & 0.76 \\
Does portal have greater revenues? & 0.14 & 0.17 & 0.08 & 1.26 \\
\hline
\end{tabular}

\begin{tabular}{|c|c|c|c|c|}
\hline \multicolumn{5}{|c|}{ Panel E: Payment Based on Advertising Revenue } \\
\hline & \multicolumn{3}{|c|}{ Average for Alliances When... } & Test \\
\hline & False & Intermediate & True & Statistic \\
\hline Is this a late agreement? & 0.48 & 0.35 & 0.42 & 1.52 \\
\hline Is most effort required of portal? & 0.30 & 0.53 & 0.36 & $* 4.97$ \\
\hline Does portal have greater reach? & 0.67 & 0.50 & 0.38 & 1.71 \\
\hline Does portal have greater revenues? & 0.48 & 0.50 & 0.38 & 0.79 \\
\hline \multicolumn{5}{|c|}{ Panel F: Payment Exclusively from Partner to Portal } \\
\hline & False & Intermediate & True & Statistic \\
\hline Is this a late agreement? & 0.65 & 0.67 & 0.81 & 2.03 \\
\hline Is most effort required of portal? & 0.83 & 0.60 & 0.64 & $* 5.53$ \\
\hline Does portal have greater reach? & 0.67 & 0.61 & 0.72 & 1.18 \\
\hline Does portal have greater revenues? & 0.62 & 0.67 & 0.72 & 0.86 \\
\hline
\end{tabular}

$*=$ Significant at the $10 \%$ confidence level; $* *=$ significant at the $5 \%$ confidence level; $* * *=$ significant at the $1 \%$ confidence level. 


\section{Table 11}

Logit regression analyses of the payment structure in portal alliances. The sample consists of 106 alliances involving Internet portals between 1995 and 1999. The dependent variables are dummy variables denoting if the payment was exclusively a fixed fee, if it was contingent on product sales, and if it was contingent on new customers or subscribers $(+1$ denoted a case where the answer to the question was affirmative and 0 a case where it was not). Independent variables include the year of the agreement, the relative effort required of the portal and partner after the alliance signing on five key dimensions (with those where the most effort is required of the portal coded as -5 and the most effort by the portal as +5$)$, the relative reach of the portal and the partner in the month before the signing of the contract ( +1 denoted a case where the portal has the greater reach, -1 those where the partner did, and 0 intermediate cases), and the relative sales of the portal and the partner in the quarter before the signing of the contract $(+1$ denoted a case where the portal has the greater sales, -1 those where the partner did, and 0 intermediate cases). Two regressions include controls for the type of the agreement and the portals entering into the agreements (not reported). Heteroskedasticconsistent standard errors in brackets.

\begin{tabular}{|c|c|c|c|c|c|}
\hline & & Depen & Variable: Is the $\mathrm{Pa}$ & yment... & \\
\hline & Just a Fi & ed Fee? & Contingent & on Sales? & $\begin{array}{l}\text { Contingent on New } \\
\text { Customers/Subscribers }\end{array}$ \\
\hline & $\begin{array}{c}\text { Basic } \\
\text { specification }\end{array}$ & $\begin{array}{c}\text { Controlling for } \\
\text { deal type \& portal }\end{array}$ & $\begin{array}{c}\text { Basic } \\
\text { specification }\end{array}$ & $\begin{array}{c}\text { Controlling for } \\
\text { deal type \& portal }\end{array}$ & $\begin{array}{c}\text { Basic } \\
\text { specification }\end{array}$ \\
\hline Year of agreement & $* * 0.52[0.25]$ & $0.37[0.46]$ & $* 0.26[0.16]$ & $0.10[0.32]$ & $0.03[0.45]$ \\
\hline Relative effort required after alliance signing & $-0.03[0.15]$ & $-0.06[0.21]$ & $* *_{-} 0.24[0.12]$ & $-0.12[0.17]$ & $-0.40[0.30]$ \\
\hline Does the portal have greater reach? & $* * * 0.89[0.20]$ & $* * * 1.14[0.47]$ & $0.09[0.23]$ & $0.23[0.45]$ & $1.05[1.18]$ \\
\hline Does the portal have greater sales? & $0.02[0.25]$ & $* * 0.53[0.26]$ & $-0.25[0.29]$ & $-0.31[0.52]$ & $* *-0.67[0.32]$ \\
\hline Did the alliance promote content? & & $-0.23[0.40]$ & & $0.39[0.64]$ & \\
\hline Did the alliance promote product sales? & & $0.07[0.69]$ & & $0.60[1.75]$ & \\
\hline Did the alliance involve a service agreement? & & $* * *-1.34[0.28]$ & & $-1.37[1.41]$ & \\
\hline Number of observations & 106 & 102 & 106 & 102 & 106 \\
\hline Log likelihood & -64.12 & -54.86 & -60.76 & -49.00 & -29.77 \\
\hline Pseudo $\mathrm{R}^{2}$ & 0.06 & 0.16 & 0.05 & 0.20 & 0.10 \\
\hline
\end{tabular}

\footnotetext{
$*=$ Significant at the $10 \%$ confidence level; $* *=$ significant at the $5 \%$ confidence level; *** = significant at the $1 \%$ confidence level.
} 


\section{Table 12}

The length of portal alliances. The sample consists of 106 alliances involving Internet portals between 1995 and 1999. Observations are divided by the date of the agreement, the relative effort required of the portal and partner, the relative reach of the portal and the partner in the month before the signing of the contract, and the relative sales of the portal and the partner in the quarter before the signing of the contract. The table presents several measures of length of the alliance: the original contract length, the length including any renewals (whether automatic or conditional), and the length that the portal and partner can extend the contract relying on unilateral renewal privileges. (All lengths are reported in months.) The rightmost column presents the test statistics from F-tests of the significance of these differences.

\begin{tabular}{|c|c|c|c|c|}
\hline \multicolumn{5}{|c|}{ Panel A: Length of Original Alliance } \\
\hline & \multicolumn{3}{|c|}{ Average Length for Alliances When... } & \multirow{2}{*}{$\begin{array}{c}\text { Test } \\
\text { Statistic }\end{array}$} \\
\hline & False & Intermediate & True & \\
\hline Is this a late agreement? & 25.2 & 20.6 & 23.9 & 0.94 \\
\hline Is most effort required of portal? & 22.4 & 23.5 & 22.0 & 0.08 \\
\hline Does portal have greater reach? & 12.0 & 15.0 & 24.5 & $* * 3.38$ \\
\hline Does portal have greater revenues? & 19.5 & 27.6 & 23.3 & 0.82 \\
\hline \multicolumn{5}{|c|}{ Panel B: Length of Alliance with Extensions } \\
\hline & \multicolumn{3}{|c|}{ Average Length for Alliances When... } & Test \\
\hline & False & Intermediate & True & Statistic \\
\hline Is this a late agreement? & 30.3 & 28.5 & 29.8 & 0.08 \\
\hline of portal? & 30.0 & 28.6 & 29.5 & 0.05 \\
\hline 1 have & 12.0 & 22.8 & 30.9 & 1.49 \\
\hline Does portal have greater revenues? & 27.6 & 33.0 & 29.6 & 0.16 \\
\hline \multicolumn{5}{|c|}{ Panel C: Length of Alliance with Extensions Unilaterally Exercisable by Portal } \\
\hline & \multicolumn{3}{|c|}{ Average Length for Alliances When... } & \\
\hline & False & Intermediate & True & Statistic \\
\hline Is this a late agreement? & 25.2 & 20.9 & 24.3 & 0.83 \\
\hline Is most effort required of portal? & 22.4 & 24.1 & 22.0 & 0.17 \\
\hline Does portal have greater reach? & 12.0 & 14.6 & 24.8 & **3.43 \\
\hline Does portal have greater revenues? & 19.5 & 27.6 & 23.6 & 0.84 \\
\hline \multicolumn{5}{|c|}{ Panel D: Length of Alliance with Extensions Unilaterally Exercisable by Partner } \\
\hline & \multicolumn{3}{|c|}{ Average Length for Alliances When... } & Test \\
\hline & False & Intermediate & True & Statistic \\
\hline Is this & 26.3 & 20.9 & 23.9 & 1.22 \\
\hline Is most effort required of portal? & 23.6 & 23.5 & 22.0 & 0.09 \\
\hline Does portal have greater reach? & 12.0 & 15.8 & 24.8 & $* 2.86$ \\
\hline Does portal have greater revenues? & 20.1 & 27.6 & 23.8 & 0.71 \\
\hline
\end{tabular}

$*=$ Significant at the $10 \%$ confidence level; $* *=$ significant at the $5 \%$ confidence level; $* * *=$ significant at the $1 \%$ confidence level. 


\section{Table 13}

Ordinary least squares regression analyses of the length of portal alliances. The sample consists of 106 alliances involving Internet portals between 1995 and 1999. The dependent variable is the original contract length (in months). Independent variables include the year of the agreement, the relative effort required of the portal and partner after the alliance signing on five key dimensions (with those where the most effort is required of the portal coded as -5 and the most effort by the portal as +5 ), the relative reach of the portal and the partner in the month before the signing of the contract (in most regressions, +1 denoted a case where the portal has the greater reach, -1 those where the partner did, and 0 intermediate cases, though in one case each the difference in the reach measures and the mean days spent in each month on the site per Internet user is used), and the relative sales of the portal and the partner in the quarter before the signing of the contract $(+1$ denoted a case where the portal has the greater sales, -1 those where the partner did, and 0 intermediate cases). Two regressions include controls for the type of the agreement and the portals entering into the agreements (not reported). Heteroskedastic-consistent standard errors in brackets.

\begin{tabular}{|c|c|c|c|c|c|}
\hline Year of agreement & $\begin{array}{c}\text { Basic } \\
\text { Specification } \\
-1.35[1.47]\end{array}$ & \multicolumn{2}{|c|}{$\begin{array}{l}\text { Exploring robustness to } \\
\text { alternative measures }\end{array}$} & $\begin{array}{l}\text { Controlling for } \\
\text { deal type } \\
-1.36[1.39]\end{array}$ & $\begin{array}{c}\text { Controlling for } \\
\text { deal type \& portal } \\
*-2.34[1.13]\end{array}$ \\
\hline Relative effort required after alliance signing & $0.06[0.57]$ & $-0.34[0.63]$ & $-0.37[0.65]$ & $-0.04[0.72]$ & $0.53[0.36]$ \\
\hline Does the portal have greater reach? & $* * * 8.89[1.96]$ & & & $* * * 9.36[1.83]$ & $* * * 9.35[1.45]$ \\
\hline Difference between portal and partner's daily usage & & & 0.35 [1.93] & & \\
\hline Does the portal have greater sales? & $1.23[2.67]$ & $2.32[2.67]$ & $2.39[2.64]$ & $1.25[2.78]$ & $2.75[3.00]$ \\
\hline Did the alliance promote content? & & & & $9.72[8.58]$ & $8.28[9.38]$ \\
\hline Number of observations & 92 & 58 & 58 & 89 & 89 \\
\hline F-statistic & $* * * 27.84$ & 1.25 & 1.23 & $* * * 30.65$ & $* * * 12.22$ \\
\hline $\mathrm{R}^{2}$ & 0.08 & 0.03 & 0.03 & 0.14 & 0.25 \\
\hline
\end{tabular}

$*=$ Significant at the $10 \%$ confidence level; $* *=$ significant at the $5 \%$ confidence level; $* * *=$ significant at the $1 \%$ confidence level. 
Table A1. The Relationship between Selected Contract Provisions

\begin{tabular}{|c|c|c|c|c|c|c|c|c|c|c|}
\hline \multirow[t]{2}{*}{ If this Contractual Provision is Present ... } & \multicolumn{10}{|c|}{... How often is this Contractual Provision Present? } \\
\hline & $\begin{array}{c}1 . \\
\text { Specificati } \\
\text { on }\end{array}$ & $\begin{array}{c}2 . \\
\text { Approval }\end{array}$ & $\begin{array}{l}\text { 3. Portal } \\
\text { Standards }\end{array}$ & $\begin{array}{l}\text { 4. Partner } \\
\text { Standards }\end{array}$ & $\begin{array}{l}\text { 5. Portal } \\
\text { "Look and } \\
\text { Feel" }\end{array}$ & $\begin{array}{l}\text { 6. Partner } \\
\text { "Look and } \\
\text { Feel" }\end{array}$ & 7. Mention & $\begin{array}{l}\text { 8. Ad } \\
\text { Copy }\end{array}$ & $\begin{array}{l}\text { 9. Specific } \\
\text { Browser }\end{array}$ & $\begin{array}{l}10 . \\
\text { Software }\end{array}$ \\
\hline \multicolumn{11}{|l|}{ Control: } \\
\hline 1. Specification of Partner Line of Business & (2. & $24 \%$ & $48 \%$ & $4 \%$ & $17 \%$ & $37 \%$ & $45 \%$ & $0 \%$ & $27 \%$ & $17 \%$ \\
\hline 2. Explicit Approval of Partner Content & 29 & & 17 & 5 & 58 & 13 & 9 & 4 & 21 & 21 \\
\hline 3. Conformance to Portal Standards & 53 & 15 & & 7 & 15 & 44 & 52 & 4 & 41 & 19 \\
\hline 4. Conformance to Partner Standards & 20 & 20 & 40 & & 40 & 20 & 0 & 0 & 20 & 0 \\
\hline 5. Portal determines site's "look and feel" & 15 & 41 & 12 & 6 & & 0 & 3 & 0 & 12 & 12 \\
\hline 6. Partner determines site's "look and feel" & 46 & 12 & 50 & 4 & 0 & & 54 & 8 & 38 & 21 \\
\hline 7. Requirement to Mention Other Party & 65 & 10 & 70 & 0 & 5 & 65 & & 15 & 35 & 20 \\
\hline 8. Approval of Advertising Copy & 0 & 33 & 33 & 0 & 0 & 67 & 100 & & 33 & 0 \\
\hline 9. Partner Required to Optimize Site for Specific Browser & 44 & 28 & 61 & 6 & 22 & 50 & 39 & 6 & & 22 \\
\hline 10. Partner Required to Use Specific Software & 36 & 36 & 36 & 0 & 29 & 36 & 29 & 0 & 29 & \\
\hline 11. Partner Required to Use Frames & 38 & 23 & 21 & 0 & 27 & 23 & 17 & 3 & 20 & 7 \\
\hline 12. Partner Required to Return User to Portal Site & 74 & 16 & 68 & 5 & 0 & 47 & 63 & 5 & 42 & 5 \\
\hline 13. Portal Receives Equity in Partner & 25 & 25 & 42 & 0 & 25 & 33 & 25 & 0 & 25 & 8 \\
\hline 14. Portal Receives Board Observation Rights & 0 & 100 & 0 & 0 & 100 & 0 & 0 & 0 & 100 & 100 \\
\hline \multicolumn{11}{|l|}{ Completeness: } \\
\hline 15. Minimum Number of Impressions & 34 & 19 & 30 & 15 & 26 & 29 & 26 & 4 & 16 & 14 \\
\hline 16. Minimum Number of Targeted Impressions & 22 & 22 & 11 & 13 & 11 & 11 & 22 & 22 & 11 & 0 \\
\hline 17. Minimum Number of Click-Throughs & 20 & 20 & 0 & 0 & 40 & 20 & 20 & 0 & 20 & 0 \\
\hline 18. Minimum Revenue & 57 & 21 & 43 & 7 & 28 & 43 & 43 & 7 & 21 & 29 \\
\hline 19. Minimum Number of New Customers & 0 & 33 & 0 & 33 & 33 & 0 & 0 & 0 & 0 & 0 \\
\hline 20, Speed Targets & 45 & 16 & 39 & 7 & 39 & 29 & 29 & 3 & 32 & 16 \\
\hline 21. Uptime Targets & 50 & 27 & 40 & 7 & 40 & 30 & 27 & 0 & 33 & 17 \\
\hline 22. Customer Service Targets & 69 & 14 & 71 & 0 & 21 & 43 & 57 & 7 & 43 & 21 \\
\hline 23. Competitive Ranking Targets & 60 & 27 & 40 & 0 & 40 & 27 & 40 & 7 & 27 & 13 \\
\hline \multicolumn{11}{|l|}{ Portal Exclusivity: } \\
\hline 24. Portal Cannot Establish Any Agreements with Competitors & 29 & 23 & 26 & 12 & 37 & 19 & 19 & 0 & 7 & 7 \\
\hline 25. Portal Cannot Establish More than N Agreements with Competitors & 22 & 22 & 11 & 0 & 11 & 44 & 11 & 0 & 22 & 33 \\
\hline 26. Portal Cannot Advertise Competitors & 41 & 18 & 24 & 12 & 41 & 29 & 24 & 0 & 18 & 18 \\
\hline 27. Portal Cannot Advertise Competitors in Certain Areas & 29 & 29 & 14 & 0 & 21 & 21 & 11 & 0 & 18 & 4 \\
\hline 28. Portal Cannot Advertise Competitors on a Continuous Basis & 25 & 0 & 0 & 25 & 0 & 50 & 25 & 0 & 0 & 0 \\
\hline 29. Portal Cannot Link to Competitors & 21 & 36 & 7 & 14 & 57 & 7 & 14 & 0 & 7 & 7 \\
\hline $\begin{array}{l}\text { 30. Portal Grants Competitors Exclusive Use of Keywords / Search } \\
\text { Terms }\end{array}$ & 20 & 40 & 0 & 25 & 20 & 20 & 0 & 0 & 0 & 0 \\
\hline 31. Portal Grants Competitors a Fraction of Keywords / Search Terms & 30 & 20 & 10 & 11 & 30 & 20 & 10 & 0 & 10 & 0 \\
\hline \multicolumn{11}{|l|}{ Partner Exclusivity: } \\
\hline 32. Partner Cannot Establish Any Agreements with Competitors & 14 & 50 & 13 & 0 & 75 & 13 & 0 & 0 & 25 & 13 \\
\hline 33. Partner Cannot Establish Certain Agreements with Competitors & 50 & 25 & 38 & 0 & 25 & 25 & 38 & 0 & 25 & 63 \\
\hline 34. Partner Cannot Advertise Competitors & 58 & 8 & 50 & 9 & 33 & 33 & 42 & 8 & 50 & 0 \\
\hline 35. Partner Cannot Advertise Competitors in Certain Areas & 67 & 11 & 56 & 0 & 0 & 44 & 56 & 0 & 33 & 11 \\
\hline 36. Partner Cannot Advertise Competitors on a Continuous Basis & 0 & 50 & 0 & 0 & 0 & 0 & 50 & 50 & 0 & 0 \\
\hline 37. Partner Must Promote Portal at least as Prominently as Competitors & 42 & 17 & 42 & 0 & 33 & 42 & 50 & 0 & 25 & 42 \\
\hline 38. Partner Cannot Link to Competitors & 80 & 10 & 40 & 0 & 10 & 20 & 40 & 10 & 40 & 0 \\
\hline \multicolumn{11}{|l|}{ 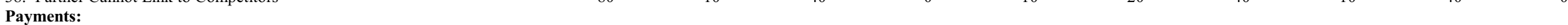 } \\
\hline 39. Fixed Payment & 33 & 22 & 31 & 9 & 22 & 28 & 19 & 3 & 19 & 0 \\
\hline 40. Payment Based on Product Sales & 42 & 16 & 30 & 0 & 19 & 32 & 29 & 3 & 26 & 16 \\
\hline 41. Payment Based on Gross Margin & 100 & 50 & 50 & 0 & 50 & 0 & 50 & 0 & 0 & 0 \\
\hline 42. Payment Based on New Customers / Subscribers & 11 & 30 & 10 & 0 & 40 & 20 & 10 & 0 & 0 & 0 \\
\hline 43. Payment Based on Advertising Revenue & 38 & 23 & 28 & 8 & 37 & 19 & 30 & 7 & 19 & 9 \\
\hline 44. Payment Exclusively from Partner to Portal & 30 & 22 & 25 & 4 & 30 & 26 & 20 & 3 & 16 & 12 \\
\hline
\end{tabular}


Table A1 (Part 2)

\begin{tabular}{|c|c|c|c|c|c|c|c|c|c|c|}
\hline \multirow[t]{2}{*}{ If this Contractual Provision is Present ... } & \multicolumn{10}{|c|}{... How often is this Contractual Provision Present? } \\
\hline & 11. Frames & $\begin{array}{c}12 . \\
\text { Return }\end{array}$ & 13. Equity & 14. Board & $\begin{array}{l}\text { 15. Imp- } \\
\text { ressions }\end{array}$ & $\begin{array}{l}\text { 16. Targ- } \\
\text { eted Imp- } \\
\text { ressions }\end{array}$ & $\begin{array}{l}\text { 17. Click- } \\
\text { Throughs }\end{array}$ & $\begin{array}{c}18 . \\
\text { Revenue }\end{array}$ & $\begin{array}{c}19 . \\
\text { Customers }\end{array}$ & 20. Speed \\
\hline \multicolumn{11}{|l|}{ Control: } \\
\hline 1. Specification of Partner Line of Business & $38 \%$ & $48 \%$ & $11 \%$ & $0 \%$ & $83 \%$ & $7 \%$ & $3 \%$ & $27 \%$ & $0 \%$ & $50 \%$ \\
\hline 2. Explicit Approval of Partner Content & 29 & 13 & 13 & 4 & 54 & 8 & 4 & 13 & 4 & 21 \\
\hline 3. Conformance to Portal Standards & 22 & 48 & 18 & 0 & 78 & 4 & 0 & 22 & 0 & 48 \\
\hline 4. Conformance to Partner Standards & 0 & 20 & 0 & 0 & 20 & 20 & 0 & 20 & 20 & 40 \\
\hline 5. Portal determines site's "look and feel" & 24 & 0 & 9 & 3 & 53 & 3 & 6 & 12 & 3 & 35 \\
\hline 6. Partner determines site's "look and feel" & 29 & 38 & 17 & 0 & 83 & 4 & 4 & 25 & 0 & 38 \\
\hline 7. Requirement to Mention Other Party & 25 & 60 & 15 & 0 & 90 & 10 & 5 & 30 & 0 & 50 \\
\hline 8. Approval of Advertising Copy & 33 & 33 & 0 & 0 & 100 & 67 & 0 & 33 & 0 & 33 \\
\hline 9. Partner Required to Optimize Site for Specific Browser & 33 & 44 & 17 & 6 & 61 & 6 & 6 & 17 & 0 & 56 \\
\hline 10. Partner Required to Use Specific Software & 14 & 7 & 7 & 7 & 71 & 0 & 0 & 29 & 0 & 38 \\
\hline 11. Partner Required to Use Frames & & 27 & 17 & 0 & 77 & 7 & 3 & 13 & 0 & 27 \\
\hline 12. Partner Required to Return User to Portal Site & 42 & & 16 & 0 & 89 & 11 & 5 & 32 & 5 & 65 \\
\hline 13. Portal Receives Equity in Partner & 42 & 25 & & 0 & 58 & 0 & 8 & 17 & 0 & 50 \\
\hline 14. Portal Receives Board Observation Rights & 0 & 0 & 0 & & 0 & 0 & 0 & 0 & 0 & 100 \\
\hline \multicolumn{11}{|l|}{ Completeness: } \\
\hline 15. Minimum Number of Impressions & 33 & 24 & 10 & 0 & & 11 & 4 & 20 & 3 & 28 \\
\hline 16. Minimum Number of Targeted Impressions & 22 & 22 & 0 & 0 & 89 & & 11 & 11 & 11 & 33 \\
\hline 17. Minimum Number of Click-Throughs & 20 & 20 & 20 & 0 & 60 & 20 & & 0 & 0 & 40 \\
\hline 18. Minimum Revenue & 29 & 43 & 14 & 0 & 100 & 7 & 0 & & 7 & 57 \\
\hline 19. Minimum Number of New Customers & 0 & 33 & 0 & 0 & 67 & 33 & 0 & 33 & & 33 \\
\hline 20, Speed Targets & 26 & 35 & 20 & 3 & 61 & 10 & 6 & 26 & 3 & \\
\hline 21. Uptime Targets & 23 & 30 & 21 & 3 & 60 & 7 & 7 & 23 & 3 & 86 \\
\hline 22. Customer Service Targets & 21 & 50 & 23 & 0 & 64 & 7 & 0 & 43 & 0 & 85 \\
\hline 23. Competitive Ranking Targets & 53 & 60 & 27 & 0 & 87 & 20 & 13 & 27 & 7 & 67 \\
\hline \multicolumn{11}{|l|}{ Portal Exclusivity: } \\
\hline 24. Portal Cannot Establish Any Agreements with Competitors & 35 & 16 & 19 & 0 & 74 & 7 & 7 & 19 & 7 & 28 \\
\hline 25. Portal Cannot Establish More than N Agreements with Competitors & 22 & 11 & 0 & 0 & 89 & 22 & 11 & 11 & 0 & 44 \\
\hline 26. Portal Cannot Advertise Competitors & 41 & 18 & 0 & 0 & 94 & 6 & 12 & 24 & 6 & 29 \\
\hline 27. Portal Cannot Advertise Competitors in Certain Areas & 46 & 21 & 14 & 0 & 79 & 11 & 7 & 14 & 0 & 25 \\
\hline 28. Portal Cannot Advertise Competitors on a Continuous Basis & 0 & 0 & 25 & 0 & 50 & 25 & 0 & 0 & 25 & 25 \\
\hline 29. Portal Cannot Link to Competitors & 43 & 0 & 7 & 0 & 86 & 21 & 14 & 7 & 7 & 0 \\
\hline $\begin{array}{l}\text { 30. Portal Grants Competitors Exclusive Use of Keywords / Search } \\
\text { Terms }\end{array}$ & 60 & 0 & 20 & 0 & 80 & 40 & 20 & 0 & 20 & 20 \\
\hline $\begin{array}{l}\text { 31. Portal Grants Competitors a Fraction of Keywords / Search Terms } \\
\text { Partner Exclusivity: }\end{array}$ & 30 & 20 & 10 & 0 & 90 & 10 & 10 & 20 & 0 & 22 \\
\hline 32. Partner Cannot Establish Any Agreements with Competitors & 25 & 13 & 13 & 13 & 50 & 0 & 13 & 13 & 25 & 25 \\
\hline 33. Partner Cannot Establish Certain Agreements with Competitors & 0 & 13 & 13 & 13 & 63 & 13 & 0 & 38 & 0 & 50 \\
\hline 34. Partner Cannot Advertise Competitors & 42 & 58 & 33 & 0 & 83 & 8 & 17 & 42 & 8 & 83 \\
\hline 35. Partner Cannot Advertise Competitors in Certain Areas & 44 & 67 & 11 & 0 & 89 & 11 & 11 & 0 & 0 & 50 \\
\hline 36. Partner Cannot Advertise Competitors on a Continuous Basis & 50 & 100 & 0 & 0 & 100 & 50 & 0 & 100 & 50 & 50 \\
\hline 37. Partner Must Promote Portal at least as Prominently as Competitors & 17 & 8 & 0 & 0 & 83 & 8 & 0 & 17 & 0 & 33 \\
\hline 38. Partner Cannot Link to Competitors & 40 & 60 & 20 & 0 & 80 & 30 & 20 & 30 & 0 & 60 \\
\hline \multicolumn{11}{|l|}{ 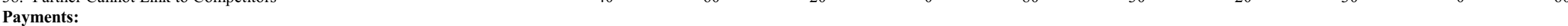 } \\
\hline 39. Fixed Payment Only & 39 & 31 & 14 & 0 & 75 & 8 & 3 & 8 & 6 & 31 \\
\hline 40. Payment Based on Product Sales & 45 & 26 & 13 & 0 & 71 & 13 & 0 & 26 & 0 & 40 \\
\hline 41. Payment Based on Gross Margin & 50 & 50 & 50 & 0 & 100 & 0 & 0 & 50 & 0 & 50 \\
\hline 42. Payment Based on New Customers / Subscribers & 30 & 0 & 20 & 0 & 60 & 0 & 10 & 0 & 10 & 20 \\
\hline 43. Payment Based on Advertising Revenue & 30 & 21 & 14 & 0 & 60 & 12 & 7 & 21 & 5 & 26 \\
\hline 44. Payment Exclusively from Partner to Portal & 34 & 19 & 8 & 0 & 77 & 12 & 7 & 12 & 3 & 29 \\
\hline
\end{tabular}


Table A1 (Part 3)

\begin{tabular}{|c|c|c|c|c|c|c|c|c|c|c|}
\hline \multirow[t]{2}{*}{ If this Contractual Provision is Present ... } & \multicolumn{10}{|c|}{... How often is this Contractual Provision Present? } \\
\hline & $\begin{array}{l}21 . \\
\text { Uptime }\end{array}$ & $\begin{array}{l}\text { 22. Cust. } \\
\text { Service }\end{array}$ & $\begin{array}{l}\text { 23. Comp } \\
\text { Ranking }\end{array}$ & $\begin{array}{l}\text { 24. No } \\
\text { Agrements }\end{array}$ & $\begin{array}{l}\text { 25. Some } \\
\text { Agreement } \\
\mathrm{s}\end{array}$ & $\begin{array}{l}\text { 26. No } \\
\text { Ads }\end{array}$ & $\begin{array}{l}\text { 27. Ban } \\
\text { Certain } \\
\text { Ads }\end{array}$ & $\begin{array}{l}\text { 28. No } \\
\text { Continuous } \\
\text { Ads }\end{array}$ & $\begin{array}{l}\text { 29. No } \\
\text { Links }\end{array}$ & $\begin{array}{l}\text { 30. Excl. } \\
\text { Keywords }\end{array}$ \\
\hline \multicolumn{11}{|l|}{ Control: } \\
\hline 1. Specification of Partner Line of Business & $53 \%$ & $32 \%$ & $35 \%$ & $41 \%$ & $7 \%$ & $24 \%$ & $27 \%$ & $3 \%$ & $10 \%$ & $3 \%$ \\
\hline 2. Explicit Approval of Partner Content & 33 & 8 & 17 & 42 & 8 & 13 & 33 & 0 & 21 & 8 \\
\hline 3. Conformance to Portal Standards & 48 & 4 & 25 & 41 & 4 & 15 & 15 & 0 & 4 & 0 \\
\hline 4. Conformance to Partner Standards & 40 & 0 & 0 & 100 & 0 & 40 & 0 & 20 & 40 & 20 \\
\hline 5. Portal determines site's "look and feel" & 35 & 9 & 18 & 47 & 3 & 21 & 18 & 0 & 24 & 3 \\
\hline 6. Partner determines site's "look and feel" & 38 & 25 & 18 & 33 & 17 & 21 & 25 & 8 & 4 & 4 \\
\hline 7. Requirement to Mention Other Party & 44 & 44 & 38 & 40 & 5 & 20 & 15 & 5 & 10 & 0 \\
\hline 8. Approval of Advertising Copy & 0 & 33 & 33 & 0 & 0 & 0 & 0 & 0 & 0 & 0 \\
\hline 9. Partner Required to Optimize Site for Specific Browser & 56 & 33 & 22 & 17 & 27 & 0 & 6 & 0 & 6 & 11 \\
\hline 10. Partner Required to Use Specific Software & 38 & 23 & 15 & 21 & 21 & 21 & 7 & 0 & 7 & 0 \\
\hline 11. Partner Required to Use Frames & 23 & 10 & 27 & 50 & 7 & 23 & 43 & 0 & 20 & 10 \\
\hline 12. Partner Required to Return User to Portal Site & 53 & 41 & 56 & 37 & 5 & 16 & 32 & 0 & 0 & 0 \\
\hline 13. Portal Receives Equity in Partner & 50 & 25 & 33 & 67 & 0 & 0 & 33 & 8 & 8 & 8 \\
\hline 14. Portal Receives Board Observation Rights & 100 & 0 & 0 & 0 & 0 & 0 & 0 & 0 & 0 & 0 \\
\hline \multicolumn{11}{|l|}{ Completeness: } \\
\hline 15. Minimum Number of Impressions & 27 & 13 & 20 & 46 & 11 & 23 & 31 & 3 & 17 & 6 \\
\hline 16. Minimum Number of Targeted Impressions & 22 & 11 & 33 & 33 & 22 & 11 & 33 & 11 & 33 & 22 \\
\hline 17. Minimum Number of Click-Throughs & 40 & 0 & 40 & 60 & 20 & 40 & 40 & 0 & 40 & 20 \\
\hline 18. Minimum Revenue & 50 & 43 & 29 & 57 & 7 & 29 & 29 & 0 & 7 & 0 \\
\hline 19. Minimum Number of New Customers & 33 & 0 & 33 & 100 & 0 & 33 & 0 & 33 & 33 & 33 \\
\hline 20. Speed Targets & 84 & 39 & 33 & 39 & 13 & 16 & 23 & 3 & 0 & 3 \\
\hline 21. Uptime Targets & & 33 & 34 & 40 & 10 & 20 & 20 & 3 & 3 & 7 \\
\hline 22. Customer Service Targets & 71 & & 38 & 43 & 0 & 21 & 14 & 0 & 0 & 0 \\
\hline 23. Competitive Ranking Targets & 67 & 33 & & 47 & 7 & 33 & 13 & 0 & 13 & 7 \\
\hline \multicolumn{11}{|l|}{ Portal Exclusivity: } \\
\hline 24. Portal Cannot Establish Any Agreements with Competitors & 28 & 14 & 16 & & 0 & 33 & 35 & 5 & 28 & 9 \\
\hline 25. Portal Cannot Establish More than N Agreements with Competitors & 33 & 0 & 13 & 0 & & 0 & 44 & 11 & 0 & 11 \\
\hline 26. Portal Cannot Advertise Competitors & 35 & 18 & 29 & 82 & 0 & & 0 & 0 & 53 & 12 \\
\hline 27. Portal Cannot Advertise Competitors in Certain Areas & 21 & 7 & 7 & 54 & 14 & 0 & & 4 & 11 & 4 \\
\hline 28. Portal Cannot Advertise Competitors on a Continuous Basis & 25 & 0 & 0 & 50 & 25 & 0 & 25 & & 25 & 25 \\
\hline 29. Portal Cannot Link to Competitors & 7 & 0 & 14 & 86 & 0 & 64 & 21 & 7 & & 29 \\
\hline $\begin{array}{l}\text { 30. Portal Grants Competitors Exclusive Use of Keywords / Search } \\
\text { Terms }\end{array}$ & 40 & 0 & 20 & 80 & 20 & 40 & 20 & 20 & 80 & \\
\hline 31. Portal Grants Competitors a Fraction of Keywords / Search Terms & 11 & 0 & 0 & 20 & 10 & 20 & 50 & 10 & 20 & 0 \\
\hline \multicolumn{11}{|l|}{ Partner Exclusivity: } \\
\hline 32. Partner Cannot Establish Any Agreements with Competitors & 25 & 13 & 13 & 63 & 0 & 25 & 13 & 0 & 13 & 0 \\
\hline 33. Partner Cannot Establish Certain Agreements with Competitors & 50 & 38 & 0 & 50 & 0 & 38 & 25 & 0 & 25 & 0 \\
\hline 34. Partner Cannot Advertise Competitors & 58 & 42 & 50 & 50 & 0 & 33 & 25 & 0 & 8 & 0 \\
\hline 35. Partner Cannot Advertise Competitors in Certain Areas & 50 & 13 & 29 & 11 & 33 & 0 & 33 & 0 & 0 & 0 \\
\hline 36. Partner Cannot Advertise Competitors on a Continuous Basis & 50 & 0 & 50 & 0 & 0 & 0 & 0 & 0 & 0 & 0 \\
\hline 37. Partner Must Promote Portal at least as Prominently as Competitors & 33 & 25 & 18 & 50 & 25 & 33 & 8 & 8 & 25 & 0 \\
\hline 38. Partner Cannot Link to Competitors & 30 & 40 & 40 & 40 & 10 & 20 & 40 & 0 & 20 & 0 \\
\hline \multicolumn{11}{|l|}{ 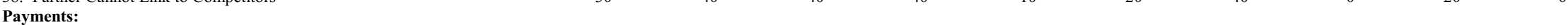 } \\
\hline 39. Fixed Payment Only & 29 & 6 & 20 & 44 & 6 & 22 & 33 & 8 & 14 & 6 \\
\hline 40. Payment Based on Product Sales & 43 & 30 & 21 & 39 & 6 & 16 & 42 & 3 & 13 & 6 \\
\hline 41. Payment Based on Gross Margin & 100 & 50 & 100 & 100 & 0 & 50 & 0 & 0 & 50 & 50 \\
\hline 42. Payment Based on New Customers / Subscribers & 30 & 10 & 10 & 80 & 0 & 20 & 50 & 10 & 0 & 0 \\
\hline 43. Payment Based on Advertising Revenue & 29 & 17 & 7 & 49 & 2 & 9 & 23 & 7 & 19 & 5 \\
\hline 44. Payment Exclusively from Partner to Portal & 23 & 14 & 17 & 47 & 9 & 23 & 34 & 4 & 18 & 7 \\
\hline
\end{tabular}


Table A1 (Part 4)

\begin{tabular}{|c|c|c|c|c|c|c|c|c|c|c|}
\hline \multirow[t]{2}{*}{ If this Contractual Provision is Present ... } & \multicolumn{10}{|c|}{... How often is this Contractual Provision Present? } \\
\hline & $\begin{array}{l}\text { 31. Some } \\
\text { Keywords }\end{array}$ & $\begin{array}{c}\text { 32. No } \\
\text { Agreement } \\
\text { s }\end{array}$ & $\begin{array}{l}\text { 33. Some } \\
\text { Agreement } \\
\mathrm{s}\end{array}$ & 34. No Ads & $\begin{array}{l}\text { 35. Restrict } \\
\text { Ads }\end{array}$ & $\begin{array}{l}\text { 36. Cont. } \\
\text { Ads }\end{array}$ & $\begin{array}{c}37 . \\
\text { Promotion }\end{array}$ & $\begin{array}{l}\text { 38. No } \\
\text { Links }\end{array}$ & $\begin{array}{l}\text { 39. Fixed } \\
\text { Payment } \\
\text { Only }\end{array}$ & $\begin{array}{l}\text { 40. Product } \\
\text { Sales }\end{array}$ \\
\hline \multicolumn{11}{|l|}{ Control: } \\
\hline 1. Specification of Partner Line of Business & $10 \%$ & $3 \%$ & $14 \%$ & $24 \%$ & $21 \%$ & $0 \%$ & $17 \%$ & $28 \%$ & $41 \%$ & $45 \%$ \\
\hline 2. Explicit Approval of Partner Content & 8 & 17 & 8 & 4 & 4 & 4 & 8 & 4 & 33 & 21 \\
\hline 3. Conformance to Portal Standards & 4 & 4 & 11 & 22 & 19 & 0 & 19 & 15 & 41 & 33 \\
\hline 4. Conformance to Partner Standards & 20 & 0 & 0 & 20 & 0 & 0 & 0 & 0 & 60 & 0 \\
\hline 5. Portal determines site's "look and feel" & 9 & 18 & 6 & 12 & 0 & 0 & 12 & 3 & 24 & 18 \\
\hline 6. Partner determines site's "look and feel" & 8 & 3 & 8 & 17 & 17 & 0 & 21 & 8 & 42 & 42 \\
\hline 7. Requirement to Mention Other Party & 5 & 0 & 15 & 25 & 25 & 5 & 30 & 20 & 35 & 45 \\
\hline 8. Approval of Advertising Copy & 0 & 0 & 0 & 33 & 0 & 33 & 0 & 33 & 33 & 33 \\
\hline 9. Partner Required to Optimize Site for Specific Browser & 6 & 11 & 11 & 33 & 17 & 0 & 17 & 22 & 39 & 50 \\
\hline 10. Partner Required to Use Specific Software & 0 & 7 & 36 & 0 & 7 & 0 & 36 & 0 & 0 & 36 \\
\hline 11. Partner Required to Use Frames & 10 & 7 & 0 & 17 & 13 & 3 & 7 & 13 & 47 & 47 \\
\hline 12. Partner Required to Return User to Portal Site & 11 & 5 & 5 & 37 & 32 & 11 & 5 & 32 & 58 & 42 \\
\hline 13. Portal Receives Equity in Partner & 8 & 8 & 8 & 33 & 8 & 0 & 0 & 17 & 42 & 42 \\
\hline 14. Portal Receives Board Observation Rights & 0 & 100 & 100 & 0 & 0 & 0 & 0 & 0 & 0 & 0 \\
\hline \multicolumn{11}{|l|}{ Completeness: } \\
\hline 15. Minimum Number of Impressions & 13 & 6 & 7 & 14 & 11 & 3 & 14 & 11 & 39 & 31 \\
\hline 16. Minimum Number of Targeted Impressions & 11 & 0 & 11 & 11 & 11 & 11 & 11 & 33 & 33 & 44 \\
\hline 17. Minimum Number of Click-Throughs & 20 & 20 & 0 & 40 & 20 & 0 & 0 & 40 & 20 & 0 \\
\hline 18. Minimum Revenue & 14 & 7 & 21 & 36 & 0 & 14 & 14 & 21 & 21 & 57 \\
\hline 19. Minimum Number of New Customers & 0 & 67 & 0 & 33 & 0 & 33 & 0 & 0 & 67 & 0 \\
\hline 20. Speed Targets & 6 & 6 & 13 & 32 & 13 & 3 & 13 & 19 & 35 & 39 \\
\hline 21. Uptime Targets & 3 & 7 & 13 & 23 & 13 & 0 & 13 & 10 & 33 & 43 \\
\hline 22. Customer Service Targets & 0 & 7 & 21 & 36 & 7 & 7 & 21 & 29 & 14 & 64 \\
\hline 23. Competitive Ranking Targets & 0 & 7 & 0 & 40 & 13 & 7 & 13 & 27 & 47 & 40 \\
\hline \multicolumn{11}{|l|}{ Portal Exclusivity: } \\
\hline 24. Portal Cannot Establish Any Agreements with Competitors & 5 & 12 & 9 & 14 & 2 & 2 & 14 & 9 & 37 & 28 \\
\hline 25. Portal Cannot Establish More than N Agreements with Competitors & 11 & 0 & 0 & 0 & 33 & 0 & 33 & 11 & 22 & 22 \\
\hline 26. Portal Cannot Advertise Competitors & 12 & 12 & 18 & 24 & 0 & 0 & 24 & 12 & 47 & 29 \\
\hline 27. Portal Cannot Advertise Competitors in Certain Areas & 18 & 4 & 7 & 11 & 11 & 0 & 4 & 14 & 43 & 46 \\
\hline 28. Portal Cannot Advertise Competitors on a Continuous Basis & 25 & 0 & 0 & 0 & 0 & 0 & 25 & 0 & 75 & 25 \\
\hline 29. Portal Cannot Link to Competitors & 14 & 7 & 14 & 7 & 0 & 0 & 21 & 14 & 36 & 29 \\
\hline $\begin{array}{l}\text { 30. Portal Grants Competitors Exclusive Use of Keywords / Search } \\
\text { Terms }\end{array}$ & 0 & 0 & 0 & 0 & 0 & 0 & 0 & 0 & 40 & 40 \\
\hline $\begin{array}{l}\text { 31. Portal Grants Competitors a Fraction of Keywords / Search Terms } \\
\text { Partner Exclusivity: }\end{array}$ & 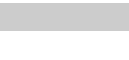 & 20 & 0 & 30 & 10 & 0 & 0 & 2 & 70 & 30 \\
\hline 32. Partner Cannot Establish Any Agreements with Competitors & 25 & & 13 & 38 & 0 & 13 & 0 & 13 & 25 & 13 \\
\hline 33. Partner Cannot Establish Certain Agreements with Competitors & 0 & 13 & & 0 & 0 & 0 & 38 & 13 & 0 & 50 \\
\hline 34. Partner Cannot Advertise Competitors & 25 & 25 & 0 & & 0 & 8 & 0 & 50 & 58 & 25 \\
\hline 35. Partner Cannot Advertise Competitors in Certain Areas & 11 & 0 & 0 & 0 & & 0 & 11 & 33 & 67 & 22 \\
\hline 36. Partner Cannot Advertise Competitors on a Continuous Basis & 0 & 50 & 0 & 50 & 0 & & 0 & 50 & 0 & 50 \\
\hline 37. Partner Must Promote Portal at least as Prominently as Competitors & 0 & 0 & 25 & 0 & 8 & 0 & & 0 & 8 & 33 \\
\hline 38. Partner Cannot Link to Competitors & 20 & 10 & 10 & 60 & 30 & 10 & 0 & & 60 & 40 \\
\hline \multicolumn{11}{|l|}{ Payments: } \\
\hline 39. Fixed Payment Only & 19 & 6 & 0 & 19 & 17 & 0 & 3 & 17 & & 14 \\
\hline 40. Payment Based on Product Sales & 10 & 3 & 13 & 10 & 6 & 3 & 13 & 13 & 16 & \\
\hline 41. Payment Based on Gross Margin & 0 & 0 & 0 & 50 & 0 & 0 & 0 & 50 & 50 & 0 \\
\hline 42. Payment Based on New Customers / Subscribers & 10 & 20 & 0 & 10 & 0 & 0 & 0 & 0 & 50 & 20 \\
\hline 43. Payment Based on Advertising Revenue & 5 & 14 & 7 & 16 & 7 & 5 & 12 & 16 & 28 & 60 \\
\hline 44. Payment Exclusively from Partner to Portal & & & & & & & & & & \\
\hline
\end{tabular}


Table A1 (Part 5)

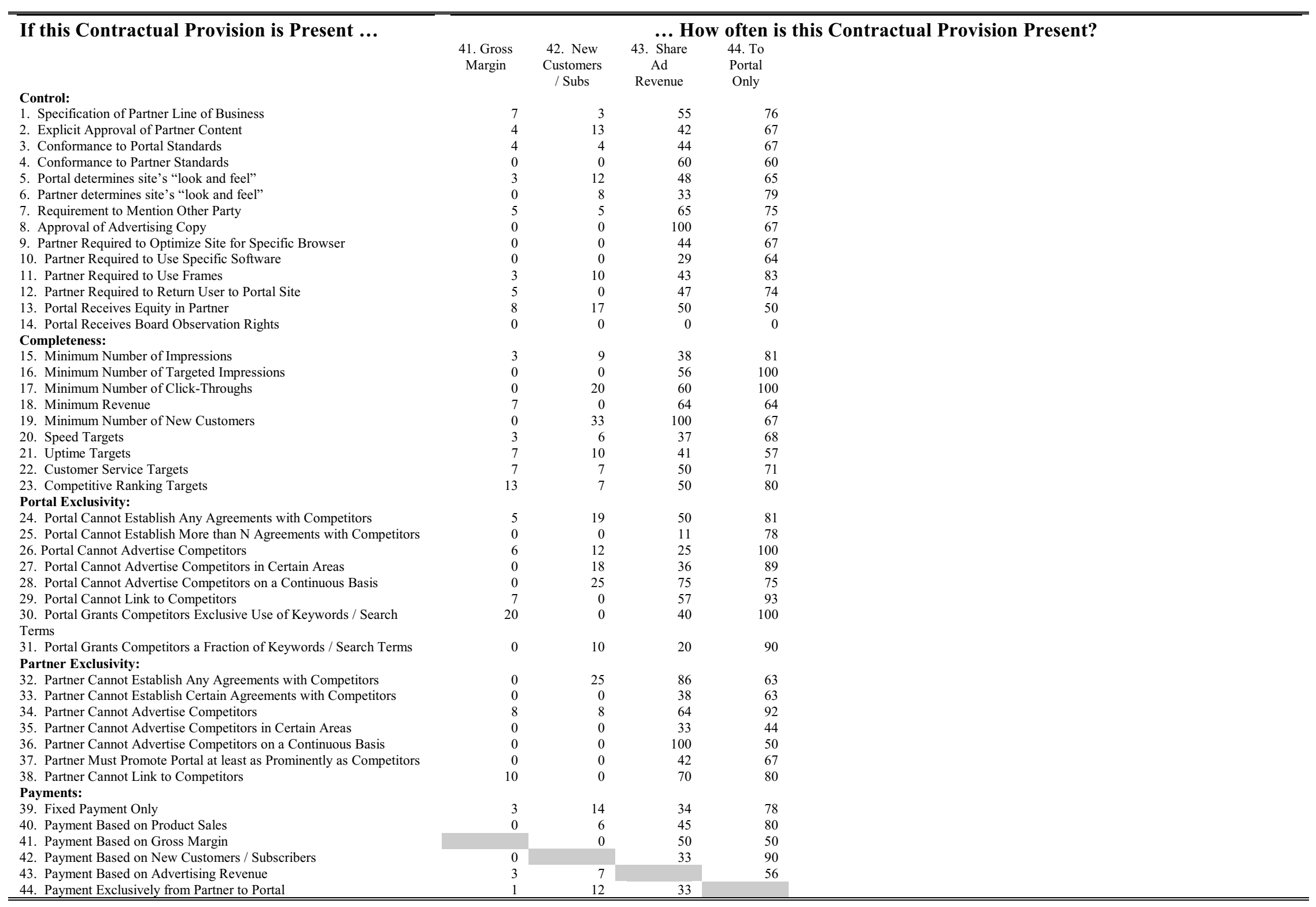




\section{Table A2}

Ordered logit regression analyses of the allocation of ownership in portal alliances for selected sub-samples. The sample consists of 106 alliances involving Internet portals between 1995 and 1999. Two types of sub-samples were analyzed. First, 46 alliances were designated as 'co-branded'; a co-branded agreement typically involved the creation of new web-pages with brands or service marks identifying both parties. Co-branded and non-cobranded contracts were analyzed separately. Second, the alliances were divided into three sub-samples depending on whether the contract focused on providing a service, content, or product sales. In 9 instances, alliances were determined to have a dual focus, which was typically content and product sales. These agreements were analyzed in both sets of regressions. The dependent variable is the sum of measures of the ownership of the URL, servers, and customer data $(+1$ denoted a case where the ownership was assigned to the portal, -1 those where it was assigned to the partner, and 0 intermediate cases.) Independent variables include the year of the agreement, the relative effort required of the portal and partner after the alliance signing on five key dimensions (with those where the most effort is required of the portal coded as -5 and the most effort by the portal as +5 ), the relative reach of the portal and the partner in the month before the signing of the contract (in most regressions, +1 denoted a case where the portal has the greater reach, -1 those where the partner did, and 0 intermediate cases, though in one case the difference in the reach measures is used), and the relative sales of the portal and the partner in the quarter before the signing of the contract (in most regressions, +1 denoted a case where the portal has the greater sales, -1 those where the partner did, and 0 intermediate cases, though in one case the difference in the actual sales in billions of 1999 dollars is used). Coefficients on the relative effort variable only are displayed. Heteroskedastic-consistent standard errors in brackets.

\begin{tabular}{|c|c|c|c|c|c|c|}
\hline & \multirow{2}{*}{$\begin{array}{c}\text { All } \\
\text { Contracts }\end{array}$} & \multicolumn{2}{|c|}{ Designation: } & \multicolumn{3}{|c|}{ Focus of Alliance } \\
\hline & & Co-branded & Not Co-branded & Service & Content & Product Sales \\
\hline \multicolumn{7}{|c|}{ Basic Specification } \\
\hline Observations & 106 & 46 & 60 & 42 & 27 & 46 \\
\hline Relative Effort & $* * * 0.65[0.06]$ & $* * * 0.76[0.14]$ & $* * * 0.71[0.08]$ & $* * 0.25[0.11]$ & $* * * 0.81[0.18]$ & $* * * 1.08[0.24]$ \\
\hline \multicolumn{7}{|c|}{ Controlling for Deal Type } \\
\hline Observations & 102 & 44 & 60 & $\mathrm{~N} / \mathrm{A}$ & N/A & $\mathrm{N} / \mathrm{A}$ \\
\hline Relative Effort & $* * * 0.57[0.07]$ & $* * * 0.64[0.16]$ & $* * * 0.67[0.14]$ & & & \\
\hline \multicolumn{7}{|c|}{ Controlling for Deal Type and Portal } \\
\hline Observations & 102 & 44 & 58 & N/A & $\mathrm{N} / \mathrm{A}$ & $\mathrm{N} / \mathrm{A}$ \\
\hline Relative Effort & $* * * 0.45[0.07]$ & $* * 0.51[0.23]$ & $* * * 0.66[0.20]$ & & & \\
\hline
\end{tabular}

$*=$ Significant at the $10 \%$ confidence level; $* *=$ significant at the $5 \%$ confidence level; $* * *=$ significant at the $1 \%$ confidence level.

\# Some alliances had two areas of focus 
Table A3

Ordered logit regression analyses of the allocation of control in portal alliances excluding content controls. The sample consists of 106 alliances involving Internet portals between 1995 and 1999. The dependent variable is the sum of nine measures of the allocation of control $(+1$ denoted a case where the control was assigned to the portal, -1 those where it was assigned to the partner, and 0 intermediate cases.) Independent variables include the year of the agreement, the relative effort required of the portal and partner after the alliance signing on five key dimensions (with those where the most effort is required of the portal coded as -5 and the most effort by the portal as +5 ), the relative reach of the portal and the partner in the month before the signing of the contract (in most regressions, +1 denoted a case where the portal has the greater reach, -1 those where the partner did, and 0 intermediate cases, though in one case each the difference in the reach measures, the mean days spent in each month on the site per Internet user, and the mean monthly minutes per Internet user are used), and the relative sales of the portal and the partner in the quarter before the signing of the contract $(+1$ denoted a case where the portal has the greater sales, -1 those where the partner did, and 0 intermediate cases). One regression includes controls for the type of the agreement. Heteroskedastic-consistent standard errors in brackets.

\section{Year of agreement}

Relative effort required after alliance signing

Does the portal have greater reach?

Difference between portal and partner's reach

Difference between portal and partner's daily usage

Difference between portal and partner's total usage

Does the portal have greater sales?

Did the alliance promote content?

Did the alliance promote product sales?

Did the alliance involve a service agreement?

Number of observations

Log likelihood

Pseudo $R^{2}$

\section{Basic \\ specification}

$$
\begin{array}{r}
019[0.22] \\
0.01[0.09]
\end{array}
$$

$* * * 0.79[0.27]$

$0.29[0.32]$

Exp
$0.20[0.43]$
$0.11[0.09]$
$* * 2.76[1.12]$

Exploring robustness to

alternative measures

$\begin{array}{llr}0.12[0.20] & 0.12[0.22] & * 0.03[0.02] \\ 0.28[0.27]\end{array}$

$* * * 0.51[0.18]$

Controlling for ontrolling for
deal type

$0.24[0.22]$

$0.00[0.09]$

$* * * 0.71[0.20]$

$0.23[0.34]$

$0.89[0.69]$

$0.73[0.56]$

$0.77[0.68]$

$\begin{array}{rrrr}104 & 64 & 64 & 64 \\ -161.34 & 95.85 & -96.04 & -98.24 \\ 0.03 & 0.05 & 0.05 & 0.02\end{array}$

$-156.13$

0.03

$*=$ Significant at the $10 \%$ confidence level; $* *=$ significant at the $5 \%$ confidence level; $* * *=$ significant at the $1 \%$ confidence level. 


\section{Table A4}

Ordered logit regression analyses of the allocation of control in portal alliances excluding content controls and "look and feel". The sample consists of 106 alliances involving Internet portals between 1995 and 1999. The dependent variable is the sum of seven measures of the allocation of control (+1 denoted a case where the control was assigned to the portal, -1 those where it was assigned to the partner, and 0 intermediate cases.) Independent variables include the year of the agreement, the relative effort required of the portal and partner after the alliance signing on five key dimensions (with those where the most effort is required of the portal coded as -5 and the most effort by the portal as +5 ), the relative reach of the portal and the partner in the month before the signing of the contract (in most regressions, +1 denoted a case where the portal has the greater reach, -1 those where the partner did, and 0 intermediate cases, though in one case each the difference in the reach measures, the mean days spent in each month on the site per Internet user, and the mean monthly minutes per Internet user are used), and the relative sales of the portal and the partner in the quarter before the signing of the contract $(+1$ denoted a case where the portal has the greater sales, -1 those where the partner did, and 0 intermediate cases). One regression includes controls for the type of the agreement. Heteroskedastic-consistent standard errors in brackets.

\begin{tabular}{|c|c|c|c|c|c|}
\hline \multirow[b]{2}{*}{ Year of agreement } & \multirow{2}{*}{$\begin{array}{c}\text { Basic } \\
\text { specification } \\
0.20[0.22]\end{array}$} & \multicolumn{3}{|c|}{$\begin{array}{l}\text { Exploring robustness to } \\
\text { alternative measures }\end{array}$} & \multirow{2}{*}{$\begin{array}{c}\text { Controlling for } \\
\text { deal type } \\
0.23[0.26]\end{array}$} \\
\hline & & $0.21[0.37]$ & $0.10[0.41]$ & $0.20[0.22]$ & \\
\hline Relative effort required after alliance signing & $-0.17[0.10]$ & $-0.07[0.10]$ & $-0.10[0.10]$ & $-0.10[0.12]$ & $-0.14[0.11]$ \\
\hline Does the portal have greater reach? & $0.40[0.37]$ & & & & $0.23[0.35]$ \\
\hline Difference between portal and partner's reach & & $* * 2.67[1.53]$ & & & \\
\hline Difference between portal and partner's daily usage & & & $* 0.54[0.28]$ & & \\
\hline Difference between portal and partner's total usage & & & & $0.02[0.02]$ & \\
\hline Does the portal have greater sales? & $* * 0.79[0.36]$ & $* * 0.69[0.23]$ & $* * * 0.67[0.22]$ & $* * * 0.85[0.28]$ & $* 0.78[0.39]$ \\
\hline Did the alliance promote content? & & & & & $0.64[0.75]$ \\
\hline Did the alliance promote product sales? & & & & & $0.66[0.46]$ \\
\hline Did the alliance involve a service agreement? & & & & & $0.22[0.72]$ \\
\hline Number of observations & 104 & 64 & 64 & 63 & 101 \\
\hline Log likelihood & -151.39 & -86.48 & -86.15 & -88.03 & -146.14 \\
\hline Pseudo $\mathrm{R}^{2}$ & 0.06 & 0.10 & 0.10 & 0.07 & 0.07 \\
\hline
\end{tabular}

$*=$ Significant at the $10 \%$ confidence level; $* *=$ significant at the $5 \%$ confidence level; $* * *=$ significant at the $1 \%$ confidence level. 